Atmos. Chem. Phys., 19, 13037-13052, 2019

https://doi.org/10.5194/acp-19-13037-2019

(C) Author(s) 2019. This work is distributed under

the Creative Commons Attribution 4.0 License.

\title{
Carboxylic acids from limonene oxidation by ozone and hydroxyl radicals: insights into mechanisms derived using a FIGAERO-CIMS
}

\author{
Julia Hammes ${ }^{1}$, Anna Lutz ${ }^{1}$, Thomas Mentel ${ }^{1,2}$, Cameron Faxon ${ }^{1}$, and Mattias Hallquist ${ }^{1}$ \\ ${ }^{1}$ Department of Chemistry and Molecular Biology, University of Gothenburg, Gothenburg, Sweden \\ ${ }^{2}$ Institute of Energy and Climate Research, Troposphere (IEK-8), Forschungszentrum Jülich GmbH, Jülich, Germany
}

Correspondence: Mattias Hallquist (hallq@ chem.gu.se)

Received: 21 September 2018 - Discussion started: 27 September 2018

Revised: 10 July 2019 - Accepted: 25 July 2019 - Published: 22 October 2019

\begin{abstract}
This work presents the results from a flow reactor study on the formation of carboxylic acids from limonene oxidation in the presence of ozone under $\mathrm{NO}_{x}$-free conditions in the dark. A High-Resolution Time-of-Flight acetate Chemical Ionisation Mass Spectrometer (HR-ToF-CIMS) was used in combination with a Filter Inlet for Gases and AEROsols (FIGAERO) to measure the carboxylic acids in the gas and particle phases. The results revealed that limonene oxidation produced large amounts of carboxylic acids which are important contributors to secondary organic aerosol (SOA) formation. The highest 10 acids contributed $56 \%-91 \%$ to the total gas-phase signal, and the dominant gas-phase species in most experiments were $\mathrm{C}_{8} \mathrm{H}_{12} \mathrm{O}_{4}$, $\mathrm{C}_{9} \mathrm{H}_{14} \mathrm{O}_{4}, \mathrm{C}_{7} \mathrm{H}_{10} \mathrm{O}_{4}$ and $\mathrm{C}_{10} \mathrm{H}_{16} \mathrm{O}_{3}$. The particle-phase composition was generally more complex than the gas-phase composition, and the highest 10 acids contributed 47\%-92\% to the total signal. The dominant species in the particle phase were $\mathrm{C}_{8} \mathrm{H}_{12} \mathrm{O}_{5}, \mathrm{C}_{9} \mathrm{H}_{14} \mathrm{O}_{5}, \mathrm{C}_{9} \mathrm{H}_{12} \mathrm{O}_{5}$ and $\mathrm{C}_{10} \mathrm{H}_{16} \mathrm{O}_{4}$. The measured concentration of dimers bearing at least one carboxylic acid function in the particle phase was very low, indicating that acidic dimers play a minor role in SOA formation via ozone $\left(\mathrm{O}_{3}\right)$ /hydroxyl $(\mathrm{OH})$ oxidation of limonene. Based on the various experimental conditions, the acidic compositions for all experiments were modelled using descriptions from the Master Chemical Mechanism (MCM). The experiment and model provided a yield of large $\left(\mathrm{C}_{7}-\mathrm{C}_{10}\right)$ carboxylic acid of the order of $10 \%(2 \%-23 \%$ and $10 \%-15 \%$, respectively). Significant concentrations of 11 acids, from a total of 16 acids, included in the MCM were measured with the CIMS. However, the model predictions were, in some cases, inconsistent with the measurement results, especially regarding the $\mathrm{OH}$ dependence. Reaction mechanisms
\end{abstract}

are suggested to fill-in the knowledge gaps. Using the additional mechanisms proposed in this work, nearly $75 \%$ of the observed gas-phase signal in our lowest concentration experiment ( 8.4 ppb converted, ca. $23 \%$ acid yield) carried out under humid conditions can be understood.

\section{Introduction}

Atmospheric aerosol particles have an impact on climate and human health, and their respective effects depend on particle properties determined by the particle size and chemical composition. Among the many constituents of atmospheric aerosol particles, organic aerosol particles are the least understood (Glasius and Goldstein, 2016). Secondary organic aerosol (SOA) is the major component of organic aerosols. Identifying the chemical pathways of condensable products is essential for predicting SOA formation (Hallquist et al., 2009; Ziemann and Atkinson, 2012; Ehn et al., 2014; Shrivastava et al., 2017; McFiggans et al., 2019). However, this identification is inherently difficult as such products often reside in both the gas and particulate phases and continuous partitioning occurs between these two phases. Low vapour pressure products from radical-initiated (i.e. $\mathrm{OH}-$ initiated) oxidation or ozonolysis of volatile organic compounds (VOCs), such as monoterpenes $\left(\mathrm{C}_{10} \mathrm{H}_{16}\right)$, contribute significantly to atmospheric aerosol particle formation and growth (Hallquist et al., 2009). Limonene, the main constituent of the essential oil from citrus plants, is a widely used chemical in personal care and household-related consumer products (owing to its pleasant smell); therefore, elevated indoor concentrations of limonene can be expected 


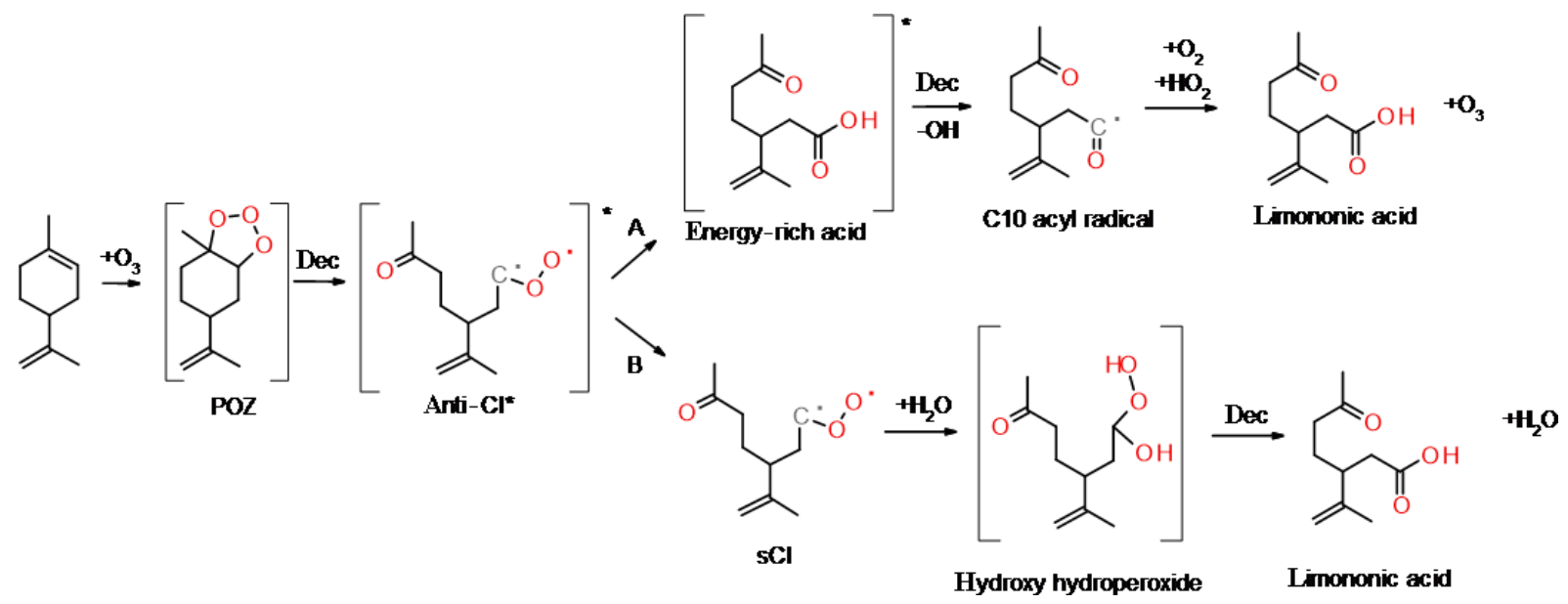

Figure 1. (a) Example of the initial reactions of limonene with ozone to form limononic acid from the anti-CI* via the hot acid channel and (b) the collisional stabilisation channel (Vereecken and Francisco, 2012).

(Brown et al., 1994; Langer et al., 2008) as well as subsequent SOA formation (Youssefi and Waring, 2014). The total global forest emission of limonene has been estimated at $11.4 \mathrm{Tg} \mathrm{yr}^{-1}$, placing it in the top four among monoterpenes (Guenther et al., 2012). A high aerosol yield and the two chemically different double bonds, an endocyclic and an exocyclic double bond, make limonene ozonolysis of specific interest (Koch et al., 2000; Saathoff et al., 2009; Chen and Hopke, 2010; Gong et al., 2018). The initial reaction predominantly occurs at the endocyclic double bond. However, the first-generation products may be unsaturated and exhibit high reactivity for further oxidation. The oxidation of limonene eventually leads to the formation of SOA in both the atmosphere and in indoor environments. The oxidation of monoterpenes and, specifically, limonene has been previously reported (Leungsakul et al., 2005a, b; Walser et al., 2008; Maksymiuk et al., 2009) and reaction mechanisms that describe first- and second-generation oxidation products have been proposed (Carslaw, 2013; Chen and Griffin, 2005). Due to their low vapour pressure, carboxylic acids, a major class of limonene-oxidation products, can play an important role in SOA formation (Salo et al., 2010). The relative contribution of carboxylic acids from limonene oxidation to SOA formation was assessed via a model by Pathak et al. (2012). According to that study, limonene ozonolysis produces significant amounts of carboxylic acids, and the distribution of these acids is affected by the $\mathrm{OH}$ and ozone concentrations.

During ozonolysis, limonene is attacked by ozone and forms an unstable and energy-rich primary ozonide, POZ (see Fig. 1). The POZ undergoes decomposition during which the oxygen atoms contribute to the formation of a carbonyl and a carbonyl oxide group, the so-called excited Criegee intermediate $\left(\mathrm{CI}^{*}\right)$. The 10 -carbon skeleton is retained during this process if an endocyclic double bond is attacked. The $\mathrm{CI}^{*}$ has a planar structure, and the orientation of the outer oxygen determines its chemical fate. The dominant reaction pathway (86\%; Atkinson et al., 1992) for limonene syn-CI* is the vinyl hydroperoxide channel (VHP) that generates an alkyl radical under the loss of an $\mathrm{OH}$ radical. This pathway provides a source for night-time $\mathrm{OH}$ in the atmosphere. The VHP requires an alkyl group in the syn position and is, hence, inaccessible to anti-CI* . The dominant fate of the anti-CI* is decomposition via the ester or the "hot acid" channel where an energy-rich ester or acid formed will undergo decomposition, resulting in various products. A possibility is formation of $\mathrm{OH}$ and an acyl radical, which can subsequently react with $\mathrm{O}_{2}$ and $\mathrm{HO}_{2}$ to form a carboxylic acid and ozone. Furthermore, the $\mathrm{CI}^{*}$ can, to some extent, become collisionally stabilised (sCI); exocyclic $\mathrm{CI}^{*}$ are stabilised more efficiently than endocyclic $\mathrm{CI}^{*}$. The $\mathrm{sCI}$ formed undergos further reactions and the $\mathrm{SCI}+$ water reaction produces a carbonyl, an alkyl or an alkoxy radical. If the sCI contains an $\alpha$-hydrogen, a carboxylic acid can be produced directly from the water reaction. Although the $\mathrm{sCI}+$ water reaction is likely the most dominant in the atmosphere, sCI may also react with carboxylic acids and form stable adducts that have been identified as dimer esters (Kristensen et al., 2016). The decomposition of $\mathrm{CI}^{*}$ can lead to the formation of alkyl radicals. These radicals rapidly react with oxygen to form alkyl peroxy radicals $\left(\mathrm{RO}_{2}\right)$, which are an important intermediate in the gas-phase oxidation of organic compounds.

The atmospheric fate of $\mathrm{RO}_{2}$ radicals in the absence of $\mathrm{NO}_{x}$ includes a self-reaction (Reactions R1-R3), isomerisation via an internal H-shift (Reaction R4) and a reaction with $\mathrm{HO}_{2}$ (Reaction 5) (Ehn et al., 2014). If $\mathrm{RO}_{2}$ is an acyl peroxy 
radical, a carboxylic acid can be formed.

$$
\begin{aligned}
\mathrm{RO}_{2}+\mathrm{RO}_{2} & \rightarrow \mathrm{RO}+\mathrm{O}_{2} \\
& \rightarrow \mathrm{ROH}+\mathrm{RCHO}+\mathrm{O}_{2} \\
& \rightarrow \mathrm{ROOR}+\mathrm{O}_{2}
\end{aligned}
$$

$\mathrm{RO}_{2}$ [internal $\mathrm{H}-$ shift $] \rightarrow \mathrm{ROOH}$

$$
\mathrm{RC}(\mathrm{O}) \mathrm{O}_{2}+\mathrm{HO}_{2} \rightarrow \mathrm{RC}(\mathrm{O}) \mathrm{OH}+\mathrm{O}_{3}
$$

These reactions lead to further functionalisation, e.g. the formation of acids, alcohols, carbonyls or peroxides, and may also produce alkoxy radicals. Subsequently, alkoxy radicals can be converted by oxygen to a carbonyl if an $\alpha$-hydrogen is present. Alkoxy radicals that lack this hydrogen will undergo isomerisation or decomposition via $\beta$-scission.

During ozonolysis experiments, $\mathrm{OH}$ radicals are produced and react with the precursor as well as the reaction products. This process occurs in the laboratory as well as in the actual atmosphere and increases the complexity of the degradation mechanisms. In the laboratory, one can scavenge the $\mathrm{OH}$ radicals produced by adding a compound, e.g. 2-butanol, that reacts rapidly with $\mathrm{OH}$, thereby reducing $\mathrm{OH}$. The $\mathrm{OH}$ scavenger reduces the $\mathrm{OH}$ concentration but leads to an increase in the $\mathrm{HO}_{2}$ and $\mathrm{RO}_{2}$ concentrations. This yields changes in the distribution of radicals and, subsequently, the radicaldependent chemistry (Keywood et al., 2004; Jonsson et al., $2008 \mathrm{~b}$ ). For example, the reaction of 2-butanol with $\mathrm{OH}$ produces $\mathrm{HO}_{2}$ radicals with a yield of $64 \%$ (MCM v3.3.1), thereby increasing the $\mathrm{HO}_{2} / \mathrm{RO}_{2}$ ratio. In laboratory experiments, these features can be employed in investigating the importance of various radicals/pathways for product distribution and subsequent SOA formation.

The Gothenburg Flow Reactor for Oxidation Studies at Low Temperatures (G-FROST) has been used in previous studies (Jonsson et al., 2006, 2008a, b; Faxon et al., 2018; Kristensen et al., 2014) to investigate the dependence of aerosol properties on different parameters (e.g. humidity and radical conditions). The G-FROST set-up has now been extended with a High-Resolution Time-of-Flight Chemical Ionisation Mass Spectrometer (HR-ToF-CIMS) that will provide insight into the chemical composition of the gas and particle phase via the connection to the Filter Inlet for Gases and AEROsols (FIGAERO). These new techniques allow for sensitive simultaneous detection in the gas and particle phases. Herein, an ionisation using acetate allows for the investigation of carboxylic acid formation. In the following, we analyse the carboxylic acid product spectrum of limonene. The goal is to detect major pathways and to compare the results with a model using the existing master chemical mechanism (MCM) that was primarily developed for gas-phase chemistry related to the impact on tropospheric ozone formation, but now is frequently used as a link to particle formation. This work considers (i) ozonolysis under dark conditions and $\mathrm{NO}_{x}$-free conditions (for various limonene concentrations) as well as the effect of humidity, $\mathrm{OH}$ scavenging and ozone level on carboxylic acid formation, and (ii) provides an outlook and suggestions for mechanistic gaps with the aim of eventually describing major acidic products found in the gas and particle phases under realistic atmospheric conditions, i.e. ozonolysis is performed in the absence of an $\mathrm{OH}$ scavenger under low concentration and humidity conditions.

\section{Materials and methods}

Oxidation studies of limonene in the presence of ozone have been performed under a variety of experimental conditions (Table 1). The experimental matrix was chosen to help understand the ozonolysis of limonene under dark, $\mathrm{NO}_{x}$-free conditions. The laminar-flow reactor approach is well-suited to investigating changes in experimental condition, e.g. dry vs. humid or high vs. low concentration. Due to the short residence time, the absolute concentration is higher than the ambient concentration even if the amount of limonene converted (a few ppb) and higher) is similar to larger simulation chamber studies. The conversion of any $\mathrm{RO}_{2}$ radicals is biased towards self-reaction, which is of importance in VOC-dominated rural forest conditions and in the indoor environment. The G-FROST system employed has been described in detail elsewhere (Jonsson et al., 2008b, a) and will only be presented briefly here. G-FROST consists of a laminar-flow reactor (a vertical Pyrex glass cylinder with a length of $191 \mathrm{~cm}$, an inner diameter $10 \mathrm{~cm}$ and a halocarbon wax coating) in a temperature-controlled housing (see Fig. S1). The total inflow into the system was $1.6 \mathrm{~L} \mathrm{~min}^{-1}$ and the sample outflow was $0.94 \mathrm{~L} \mathrm{~min}^{-1}$, yielding an average residence time of $240 \mathrm{~s}$. The aerosol was sampled with a funnel system from the centre part of the laminar flow, to minimise wall effects. Limonene (Alfa Aesar, $(\mathrm{R})-(+)-$ limonene, $97 \%$ ) was added by passing synthetic air (laboratory zero air generator, N-GC-6000, Linde Gas) through a characteristic diffusion source. Limonene was then premixed with a dry or humidified bulk flow, with or without 2-butanol (Merck, p.a. > 99\%) as an OH scavenger. During each experiment, limonene concentrations were increased stepwise $(15,40,150 \mathrm{ppb})$, while the temperature inside G-FROST was kept constant at $20^{\circ} \mathrm{C}$ for either dry, relative humidity $(\mathrm{RH})<2 \%$, or $40 \% \mathrm{RH}$ conditions. Ozone $(400,1000$, $5000 \mathrm{ppb}$ ) was generated by passing oxygen gas through a set of Pen-Ray ${ }^{\circledR}$ mercury lamps (UVP, $\lambda 254 \mathrm{~nm}$ ) and was added to G-FROST through a separate $6 \mathrm{~mm}$ Teflon line. The ozone level was kept constant during each experimental run.

A summary of the experimental conditions is provided in Table 1. The product distribution in the gas and particle phases was analysed with an acetate HR-ToF-CIMS (Aerodyne) (Bertram et al., 2011) coupled to the FIGAERO inlet (Lopez-Hilfiker et al., 2014). The reagent ion acetate is especially susceptible to acidic organic compounds such as carboxylic acids (Bertram et al., 2011). One may note that proxy acids also have high sensitivities (Lopez-Hilfiker et al., 2015) 


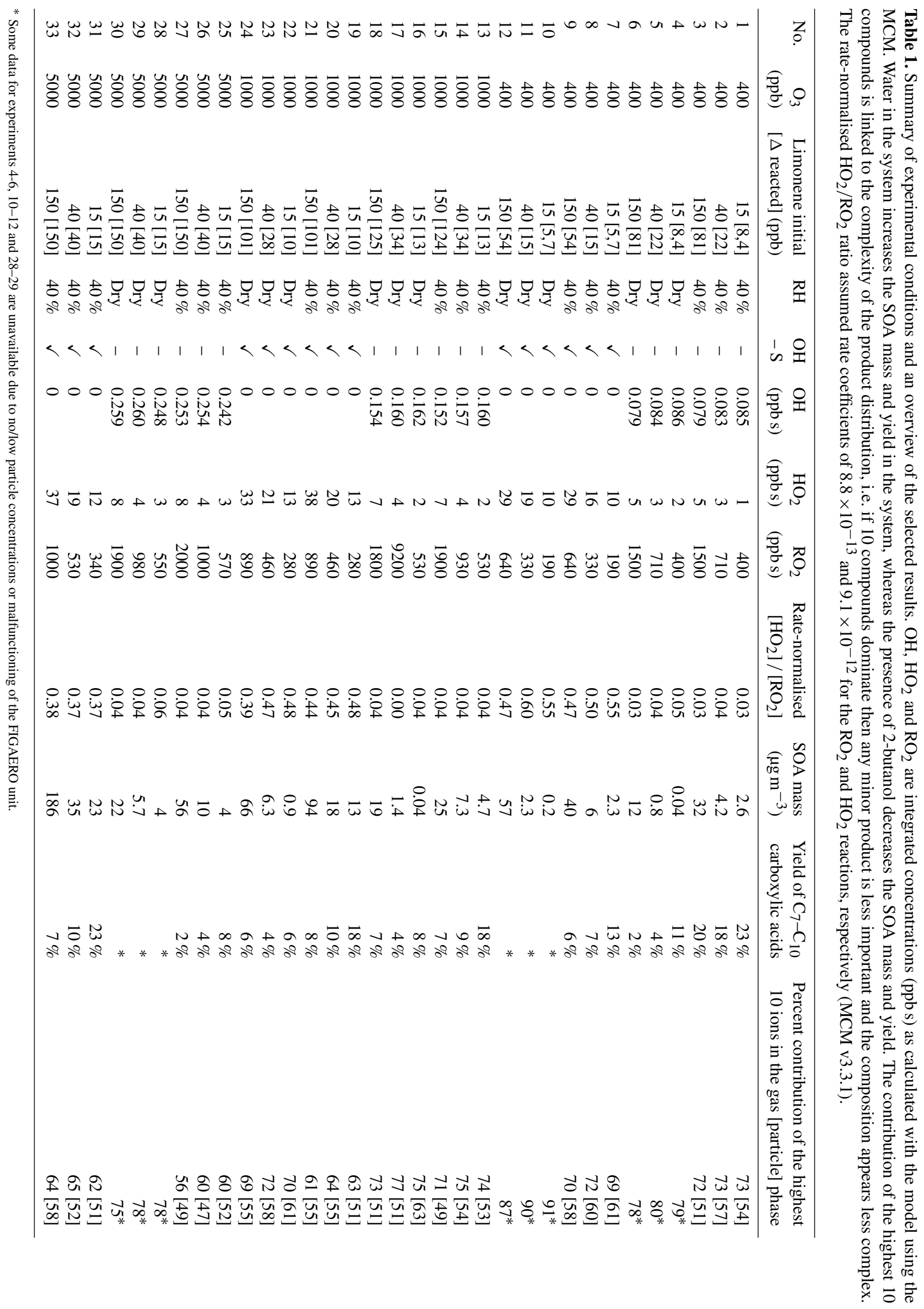


and that acetate ionisation has previously been used to detect nitro phenols (Mohr et al., 2013; Le Breton et al., 2019) and organic sulfates (Le Breton et al., 2019). However, here we assume carboxylic acids and peroxy acids to be the primarily compounds observed with the current set-up of the CIMS. The sensitivity used for larger carboxylic acids was $5.5 \times 10^{-3} \mathrm{~Hz} \mathrm{ppt}^{-1}$ (Le Breton et al., 2019). This sensitivity was used to estimate molar yields; even if one is cautious to provide absolute yields from this type of study, it provides indications on the product contribution. The sample flow from G-FROST was diluted with ultra-high purity (UHP) nitrogen gas and pumped at $2 \times 4 \mathrm{~L} \mathrm{~min}^{-1}$ by two diaphragm pumps (KNF, N816.3KN.18) through the FIGAERO inlet. The dilution was necessary for analytical reasons and might evaporate some of the most volatile compounds from the condensed phase. However, the time between the dilution and the analysis was short $(<1 \mathrm{~s})$, exactly the same for all conditions and a possible effect would somewhat mimic atmospheric conditions. Perfluoroheptanoic acid (Sigma Aldrich, $99 \%$ ) was used as the internal mass calibration standard. The gas-phase composition was determined via $60 \mathrm{~min}$ measurements, and particles were collected simultaneously on a $1 \mu \mathrm{m} 24 \mathrm{~mm}$ Zefluor ${ }^{\circledR}$ PTFE filter (Pall Corporation). During desorption, the temperature was increased from 25 to $200^{\circ} \mathrm{C}$ over a $50 \mathrm{~min}$ period $\left(3.5^{\circ} \mathrm{C} \mathrm{min}{ }^{-1}\right)$ and kept constant at $200^{\circ} \mathrm{C}$ for $10 \mathrm{~min}$. Subsequently, UHP nitrogen gas was bubbled (flow rate: $0.02 \mathrm{~L} \mathrm{~min}^{-1}$ ) through acetic anhydride (Sigma Aldrich, Puriss p.a. $\geq 99 \%$ ) and diluted with a bulk flow of UHP nitrogen to $2.2 \mathrm{~L} \mathrm{~min}^{-1}$. This flow was reduced to $2 \mathrm{~L} \mathrm{~min}^{-1}$ using a critical orifice (O'Keefe Controls Co) and passed through a commercial ${ }^{210} \mathrm{Po}$ alpha emitter (NDR, P-2021) to produce acetate reagent ions. A scanning mobility particle sizer (SMPS; CPC 3775 and DMA 3081, TSI Inc.) was used to measure the particle size distribution. The mass of the aerosol produced was determined, assuming a particle density of $1.4 \mathrm{~g} \mathrm{~cm}^{-3}$ (Hallquist et al., 2009). The CIMS data were analysed using the Tofware package (Tofwerk/Aerodyne) for Igor Pro (WaveMetrics). The data were acquired at $1 \mathrm{~Hz}$ and pre-averaged to $0.0167 \mathrm{~Hz}(1 \mathrm{~min})$ for further analysis. To account for thermal decomposition (double or triple peaks in the desorption profile), the average (four desorption cycles per reaction condition) FIGAERO desorption profiles (thermograms) were analysed in Python 3.6.0 using the NumPy (v1.11.3), SciPy library (v0.18.1) and pandas (v0.19.2) packages. The exponentially modified Gaussian function (Foley and Dorsey, 1984) was used as a peak shape function for peak fitting of the thermograms (Fig. S2). The area of the fitted peaks was calculated by integrating along the given axis using the composite trapezoidal rule. A Spearman correlation analysis was carried out based on major products, experimental conditions and calculated radical concentrations. Compared with a standard correlation, the Spearman correlation is more robust to outliers and independent of any assumptions about the distribution of the data. Therefore, it was preferred to assess the degree of as- sociation between each dominant acid and the experimental parameters. The evaluation using a Spearman correlation is similar to other correlation methods giving $0,-1$ and 1 for no correlation, a perfect negative correlation and a perfect positive correlation, respectively. All experiments have been modelled utilising an open access mechanism (MCM v3.3.1; see Table 1 for the initial conditions). The initial concentration of 2-butanol was set to $3 \times 10^{5} \mu \mathrm{g} \mathrm{m}^{-3}$ for the $\mathrm{OH}$ scavenger experiments (Pathak et al., 2012). Based on the calculations, the amount of reacted limonene was derived. The $\mathrm{OH}, \mathrm{HO}_{2}$ and $\mathrm{RO}_{2}$ levels that enabled the calculation of the corresponding values integrated over a reaction time of 240 $\mathrm{s}$ were used in the Spearman correlation analysis.

\section{Results and discussion}

A total of 33 different experiments were performed under various reaction conditions (Table 1). In the following, we will characterise the distribution of gas- and particle-phase organic acid. Figure 2 shows an example of a mass spectrum from one of the experiments. This experiment was carried out at medium-ozone and high-limonene concentrations with an estimated $8 \%$ molar yield of large carboxylic acids. Over 100 different molecular formulas for acids were still identified, far exceeding the number of acids reported in previous studies (Leungsakul et al., 2005a; Jaoui et al., 2005, 2006; Rossignol et al., 2012, 2013; Walser et al., 2008; Glasius et al., 2000). Here, we focus on the analysis of acids with carbon numbers ranging from 7 to 10 (and the dimers formed from these acids). Typically, these acids represent $2 \%-23 \%$ of the reacted limonene on a molar basis, assuming an average reaction time and CIMS sensitivity (Table 1). The distribution between the gas and particle phase varied between compounds where the average particle fraction was between $5 \%$ and $80 \%$ depending on experimental conditions. The contribution of each acid to the total signal is calculated, and the highest 10 ion signals are selected from each experiment. This gave a total of 32 different molecular compositions, representing the greatest fraction $(47 \%-91 \%)$ of the total signal.

The fraction corresponding to the sum of the 10 highest ions to the total signal can reveal the diversity of the product distribution for each condition. A low coverage indicates an experiment where several compounds with the same intensities are generated. Figure 3 shows the fraction of the 10 most prevalent ions for the comparable data to Fig. 2 (medium ozone, high limonene). This was the most complete sub-step (dry-humid, with and without scavenger) of the total matrix and the illustrated pairwise features (e.g. dry vs. humid) that were also common among other concentrations (e.g. for other condition we had missing particle-phase data, see Table 1). For these four selected experiments the estimated total yields of larger carboxylic acids $\left(\mathrm{C}_{7}-\mathrm{C}_{10}\right)$ were very similar: $6 \%$ 


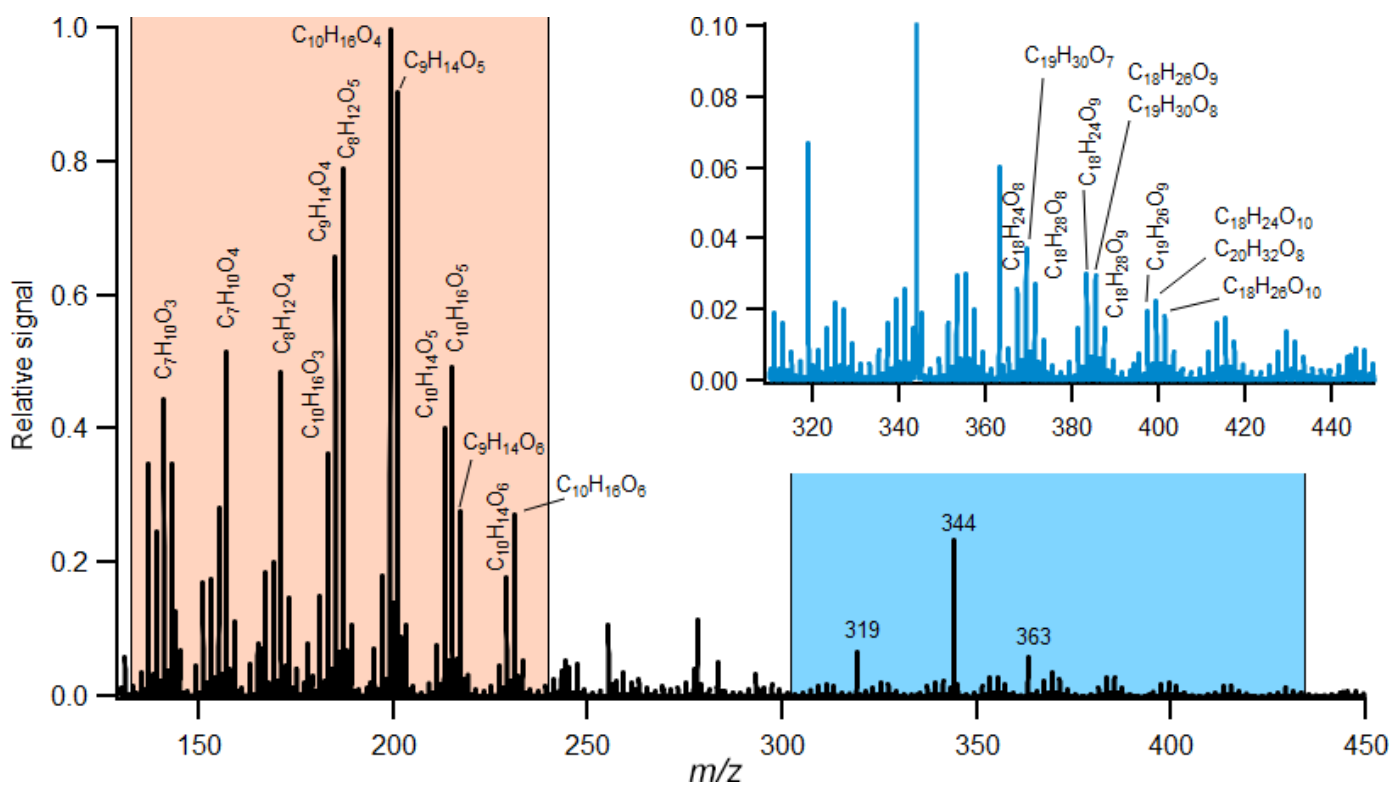

Figure 2. Example of derived mass spectra of the condensed phase taken from the experiment (Experiment no. 21) with medium-ozone and high-limonene conditions with added $\mathrm{OH}$ scavenger. The regions with identified monomers (orange region) and selected dimers (blue region) are indicated. The peaks at 319, 344 and 363 are associated with the HPFA used for mass calibration. The complexity of this mass spectra is described using the fraction of 10 dominant product ions, and the spectra are compared to other experiments with similar conditions in Fig. 3.

(dry, scavenger), $8 \%$ (humid, scavenger), $6 \%$ (dry, no scavenger) and $7 \%$ (humid, no scavenger).

In general, the particle-phase composition is more diverse (less dominated by the 10 top compounds) than the gasphase composition (Fig. 3). The presence of water in the system also increases the diversity of the product distribution in both the gas and the particle phases, i.e. a small effect in Fig. 3 but consistent for all pairwise dry/humid experiments as shown in Table 1. Compared with lower ozone concentrations, higher concentrations generally give larger product diversity, owing to the greater possibility for exocyclic doublebond oxidation or unsaturated-acid oxidation that yields a wider variety of products. The $\mathrm{OH}$ reaction pathways are suppressed in experiments with an $\mathrm{OH}$ scavenger and the oxidation can then only occur via ozonolysis. This apparently reduces the oxidation product diversity of the particle phase, which is consistent with the findings of Watne et al. (2017). In that study, the volatility of limonene SOA produced via ozonolysis only was found to be more homogeneous than that of limonene produced via other/additional processes.

Figure 4 shows the total molar yield of the acids identified in this study. One may note that the absolute yield presented here has significant uncertainties, although the relative importance of an acid can guide us in our mechanistic interpretation. Generally, the most important acids (averaged over all experiments) are $\mathrm{C}_{7} \mathrm{H}_{10} \mathrm{O}_{3}, \mathrm{C}_{7} \mathrm{H}_{10} \mathrm{O}_{4}, \mathrm{C}_{8} \mathrm{H}_{12} \mathrm{O}_{4}, \mathrm{C}_{8} \mathrm{H}_{12} \mathrm{O}_{5}$, $\mathrm{C}_{9} \mathrm{H}_{14} \mathrm{O}_{4}, \mathrm{C}_{9} \mathrm{H}_{14} \mathrm{O}_{5}, \mathrm{C}_{10} \mathrm{H}_{16} \mathrm{O}_{3}$ and $\mathrm{C}_{10} \mathrm{H}_{16} \mathrm{O}_{4}$ with yields at or below $1 \%$, which is in line with the yield of major acids in the study of Glasius et al. (2000). The most important acids in the present study are compared with an overview (Table S1) of previously reported carboxylic acids $\left(\mathrm{C}_{7}-\mathrm{C}_{10}\right)$ resulting from limonene ozonolysis. Table $\mathrm{S} 1$ also illustrates the proposed structures of these acids based on the current literature. A total of 10 of the previously reported acid formulas are found in this study, while 3 acids, $\mathrm{C}_{7} \mathrm{H}_{10} \mathrm{O}_{6}, \mathrm{C}_{8} \mathrm{H}_{12} \mathrm{O}_{6}$ and $\mathrm{C}_{8} \mathrm{H}_{14} \mathrm{O}_{4}$, lie outside the 10 highest corresponding ions identified in any of our 33 experiments. Leungsakul et al. (2005a) and Walser et al. (2008) reported that $\mathrm{C}_{9} \mathrm{H}_{14} \mathrm{O}_{4}$ and $\mathrm{C}_{10} \mathrm{H}_{16} \mathrm{O}_{3}$ were the most and second-most dominant particle-phase compounds, respectively. However, in our study, the more oxidised (compared with $\mathrm{C}_{9} \mathrm{H}_{14} \mathrm{O}_{4}$ and $\mathrm{C}_{10} \mathrm{H}_{16} \mathrm{O}_{3}$ ) compounds, $\mathrm{C}_{9} \mathrm{H}_{14} \mathrm{O}_{5}$ and $\mathrm{C}_{10} \mathrm{H}_{16} \mathrm{O}_{4}$, are the dominant in the particle-phase. From Fig. 4 it is evident that the composition of acids is very complex and many compounds contribute to the total signal. Furthermore, among the most prominent acids, there is no acid that clearly dominates in any of the experiments. We should also remember that, in addition to the acids, there are many other product categories contributing to the product distribution, e.g. recently, Gong et al. (2018) carried out a similar study focusing on peroxides and carbonyls. Utilising the complexity to further understand the mechanism requires some strategy. Here we decide to start with the 10 most prominent ions for each experiment. Thus, we created a correlation matrix of 32 different molecular compositions, where each composition might include several isomers. The intensities measured for each compound are presented in the Supplement (Tables S2 and S3). In Figs. S3-S4, we show the corresponding corre- 


\section{Gas phase}

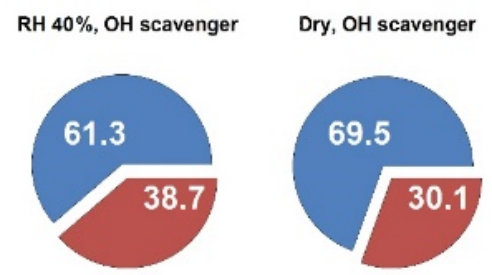

RH $40 \%$, no OH scavenger

Dry, no $\mathrm{OH}$ scavenger
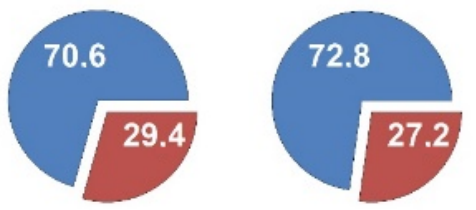

RH $40 \%$, no OH scavenger

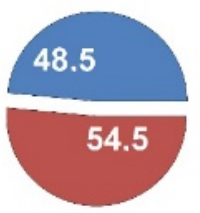

Particle phase

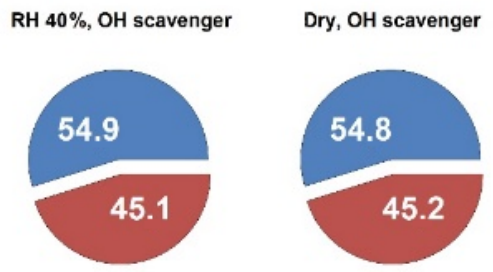

Dry, no $\mathrm{OH}$ scavenger

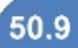

49.1

Percentage contribution of top 10 compounds to total signal

Percentage signal not explained by top 10 compounds

Figure 3. Contribution of the highest 10 compounds (blue) to the total signal in the gas and particle phase. The red fraction shows the signal not explained by the 10 highest compounds. Thus, a larger red fraction indicates a more complex composition. Data are shown for selected experiments with $1000 \mathrm{ppb}$ ozone and $150 \mathrm{ppb}$ limonene under different conditions. The estimated total yield of larger carboxylic acids $\left(\mathrm{C}_{7}-\mathrm{C}_{10}\right)$ for these four experiments were very similar: $6 \%$ (dry, scavenger), $8 \%$ (humid, scavenger), $6 \%$ (dry, no scavenger) and $7 \%$ (humid, no scavenger).

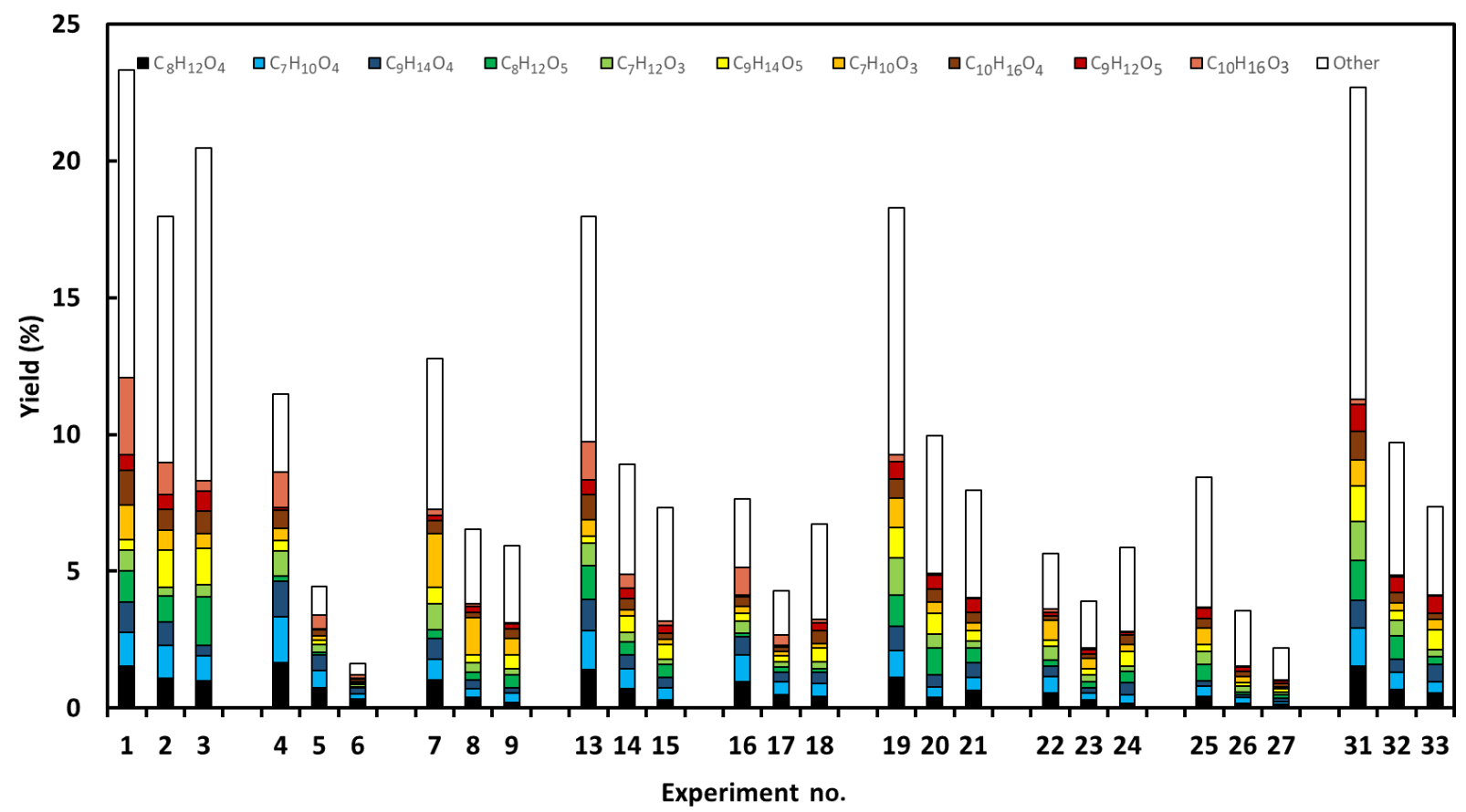

Figure 4. The molar yields of identified $\mathrm{C}_{7}-\mathrm{C}_{10}$ acids. The most important acids (averaged over all experiments) are $\mathrm{C}_{7} \mathrm{H}_{10} \mathrm{O}_{3}, \mathrm{C}_{7} \mathrm{H}_{10} \mathrm{O}_{4}$, $\mathrm{C}_{8} \mathrm{H}_{12} \mathrm{O}_{4}, \mathrm{C}_{8} \mathrm{H}_{12} \mathrm{O}_{5}, \mathrm{C}_{9} \mathrm{H}_{14} \mathrm{O}_{4}, \mathrm{C}_{9} \mathrm{H}_{14} \mathrm{O}_{5}, \mathrm{C}_{10} \mathrm{H}_{16} \mathrm{O}_{3}$ and $\mathrm{C}_{10} \mathrm{H}_{16} \mathrm{O}_{4}$ and are illustrated using individual colours (see legend). Experiments 10-12 and 28-30 were removed due to uncompleted particle-phase characterisation. 
lations, using Spearman ranking, for each of the 32 different molecular compositions representing the majority of the ion signals both with and without $\mathrm{OH}$ scavenger (Fig. S3) and for both humid and dry conditions (Fig. S4). The results for the eight most important acid formulas, i.e. $\mathrm{C}_{7} \mathrm{H}_{10} \mathrm{O}_{3}, \mathrm{C}_{7} \mathrm{H}_{10} \mathrm{O}_{4}$, $\mathrm{C}_{8} \mathrm{H}_{12} \mathrm{O}_{4}, \mathrm{C}_{8} \mathrm{H}_{12} \mathrm{O}_{5}, \mathrm{C}_{9} \mathrm{H}_{14} \mathrm{O}_{4}, \mathrm{C}_{9} \mathrm{H}_{14} \mathrm{O}_{5}, \mathrm{C}_{10} \mathrm{H}_{16} \mathrm{O}_{3}$ and $\mathrm{C}_{10} \mathrm{H}_{16} \mathrm{O}_{4}$, are presented and discussed. These are all oxidation products with a mass ranging from $130 \mathrm{~m} / z$ to $250 \mathrm{~m} / \mathrm{z}$ and are identified as carboxylic acids with carbon numbers $\leq 10$. Based on other studies (Kristensen et al., 2013, 2014, 2016; Mohr et al., 2017; Witkowski and Gierczak, 2014), dimer formation is expected. These dimers are expected to contribute significantly to the particle phase. For the particlephase data, compounds with mass above $300 \mathrm{~m} / \mathrm{z}$ are detected and are classified as dimer species if they have a carbon numbers $>10$. These compounds only occur in the particle phase; however, the relative signals are significantly lower than those reported for dimer formation in a study on limonene with nitrate radicals (Faxon et al., 2018) or the ozonolysis of other terpenes such as $\alpha$-pinene (Kristensen et al., 2016). In the present study the identified products must be acids, as we apply CI using the acetate ion. We conclude that, although dimer formation may occur (in general), no important acidic dimers are formed in the system. Consequently, we will focus on the formation of the monomer acids.

\subsection{Water effect}

Generally, most of the 32 top ions have higher signals in humidity experiments than in other environments (see Tables S2 and S3 and the correlation matrix in Fig. S4). The opposite is true for the $400 \mathrm{ppb}$ ozonolysis-only ( $\mathrm{OH}-$ scavenged) cases (gas and particle phases). For experiments with $\mathrm{OH}$ scavenger, the importance of water is evidenced by the prominent formation of gas-phase $\mathrm{C}_{10} \mathrm{H}_{16} \mathrm{O}_{3}, \mathrm{C}_{9} \mathrm{H}_{16} \mathrm{O}_{3}$, $\mathrm{C}_{9} \mathrm{H}_{1} 4 \mathrm{O}_{3}$ and $\mathrm{C}_{8} \mathrm{H}_{14} \mathrm{O}_{3}$. The water dependence of these acids is less pronounced in the mixed oxidation cases (except for $\mathrm{C}_{8} \mathrm{H}_{14} \mathrm{O}_{3}$ ), than in other cases, but water seems to be favourable for the formation of other acids, such as $\mathrm{C}_{8} \mathrm{H}_{10} \mathrm{O}_{4-5}$ and $\mathrm{C}_{7} \mathrm{H}_{10} \mathrm{O}_{2-3}$. In general, water enhances the formation of the particle-phase acids. This concurs with the findings of Jonsson et al. (2006), who reported an increase in the SOA number and mass under humid conditions. The authors attributed this to (i) an increase in the number of lowvolatility products with increasing water concentration during the ozonolysis of limonene, and (ii) the water effect on SOA formation to $\mathrm{C}_{10} \mathrm{H}_{16} \mathrm{O}_{3}$ formation. For the humidity experiments considered in the present study, we observe a considerable increase and a slight increase in the formation of gas-phase $\mathrm{C}_{10} \mathrm{H}_{16} \mathrm{O}_{3}$ and particle-phase $\mathrm{C}_{10} \mathrm{H}_{16} \mathrm{O}_{3}$, respectively. Assuming that the humidity effect on $\mathrm{C}_{10} \mathrm{H}_{16} \mathrm{O}_{3}$ production is responsible for the SOA dependence on humidity, the subsequent transformation of condensed material is required as the particulate phase is deficient in $\mathrm{C}_{10} \mathrm{H}_{16} \mathrm{O}_{3}$.

\subsection{Radical effect}

Consistent with previously reported results on the SOA mass (Jonsson et al., 2008b; Pathak et al., 2012), the intensities of most acids in the low- and medium-ozone cases are higher for experiments employing mixed oxidation than for experiments employing an $\mathrm{OH}$ scavenger. For low-ozone and lowVOC experiments, the scavenger-provided SOA mass decreases with 2-butanol addition, as previously reported by Jonsson et al. (2008a), although the effect observed here is weaker than the effect reported in that work. However, for relatively high concentrations of limonene, the opposite effect is observed, i.e. the SOA mass increases with the use of a scavenger. Notably, this effect occurs independently of the acid-intensity behaviour, and may have resulted from the fact that (i) the SOAs associated with mixed oxidation are quite volatile and (ii) increased oxidation in the presence of $\mathrm{OH}$, rather than converting semi-volatiles to low/extremely low volatiles, converts volatiles/intermediate volatiles to semivolatile species, as suggested by Pathak et al. (2012); these species are then lost during the dilution process. Another possibility is that changes in the chemistry affect nucleation, as indicated by a size-distribution shift to smaller sizes which (compared with larger sizes) are more susceptible to evaporative losses in the dilution step. Separation of these effects during the experiments is impossible; hence, the SOA formation potential associated with mixed oxidation may have been underestimated in this study. Owing to the sufficiently low ozone levels employed in the low and medium experiments, $\mathrm{OH}$ has an influence on the reaction pathways. At the highest ozone level, however, the intensities of acids associated with mixed oxidation are lower than those resulting from the use of an $\mathrm{OH}$ scavenger. To investigate the effect of radical chemistry on the reaction pathways leading to the observed carboxylic acids, the $\mathrm{OH}, \mathrm{HO}_{2}$ and $\mathrm{RO}_{2}$ concentrations are calculated and integrated using the model for each experiment (Table 1). Regarding correlation (Fig. S3), a comparison of the mixed oxidation cases reveals that the formation of most gas-phase acids (e.g. $\mathrm{C}_{10} \mathrm{H}_{16} \mathrm{O}_{3}, \mathrm{C}_{9} \mathrm{H}_{14} \mathrm{O}_{4}$ and $\mathrm{C}_{7} \mathrm{H}_{10} \mathrm{O}_{3}$ ) decreases with an increase in the amount of $\mathrm{OH}$ radicals in the system. The $\mathrm{HO}_{2} / \mathrm{RO}_{2}$ ratio only has a small influence on the mixed oxidation. However, when an $\mathrm{OH}$ scavenger is used, the amount of gas-phase products $\left(\mathrm{C}_{10} \mathrm{H}_{16} \mathrm{O}_{3}, \mathrm{C}_{10} \mathrm{H}_{16} \mathrm{O}_{4}, \mathrm{C}_{9} \mathrm{H}_{14} \mathrm{O}_{4}\right.$ and $\left.\mathrm{C}_{8} \mathrm{H}_{14} \mathrm{O}_{3}\right)$ decreases considerably with increasing $\mathrm{HO}_{2} / \mathrm{RO}_{2}$. The general influence of $\mathrm{OH}$ on acid formation is most pronounced for experiments performed under dry conditions. Under these conditions, $\mathrm{OH}$ and $\mathrm{HO}_{2} / \mathrm{RO}_{2}$ have a significant effect on the formation of $\mathrm{C}_{10} \mathrm{H}_{16} \mathrm{O}_{3}, \mathrm{C}_{9} \mathrm{H}_{14} \mathrm{O}_{3}$ and $\mathrm{C}_{7} \mathrm{H}_{10} \mathrm{O}_{4}$. For example, $\mathrm{C}_{10} \mathrm{H}_{16} \mathrm{O}_{3}$ and $\mathrm{C}_{9} \mathrm{H}_{14} \mathrm{O}_{3}$ formation increases with increasing $\mathrm{OH}$ and decreasing $\mathrm{HO}_{2} / \mathrm{RO}_{2}$. The opposite is true for $\mathrm{C}_{7} \mathrm{H}_{10} \mathrm{O}_{4}$ formation, which decreases with increasing $\mathrm{OH}$ and decreasing $\mathrm{HO}_{2} / \mathrm{RO}_{2}$. 


\subsection{Effect of excess ozone}

Experiments with high ozone levels are performed to assess the effect of excess ozone on acidic oxidation products. The aim is to oxidise (with ozone) the remaining double bond of the unsaturated carboxylic acids produced. The results show that ozone has a distinct negative impact on $\mathrm{C}_{7} \mathrm{H}_{10} \mathrm{O}_{2-3}$ in the pure ozonolysis cases (see correlation matrix in Fig. S3); hence, we conclude that those compounds are unsaturated. Furthermore, the levels of gas-phase $\mathrm{C}_{10} \mathrm{H}_{16} \mathrm{O}_{3}, \mathrm{C}_{9} \mathrm{H}_{16} \mathrm{O}_{3}$, $\mathrm{C}_{9} \mathrm{H}_{14} \mathrm{O}_{3-4}$ and $\mathrm{C}_{8} \mathrm{H}_{14} \mathrm{O}_{3}$ are positively correlated with ozone in the absence of $\mathrm{OH}$. For $\mathrm{C}_{10} \mathrm{H}_{16} \mathrm{O}_{3}$, this is surprising as this compound is assumed to be limononic acid, which is an unsaturated compound. This positive correlation may have resulted from the fact that the production of $\mathrm{C}_{10} \mathrm{H}_{16} \mathrm{O}_{3}$ dominates over the removal (via ozonolysis) of the remaining double bond. The correlation with ozone is negative for most acids in the presence of $\mathrm{OH}$ and is most pronounced for gas-phase $\mathrm{C}_{10} \mathrm{H}_{16} \mathrm{O}_{3}, \mathrm{C}_{9} \mathrm{H}_{14} \mathrm{O}_{3}$ and $\mathrm{C}_{8} \mathrm{H}_{12} \mathrm{O}_{3}$. The negative ozone correlation observed for mixed oxidation cases considering $\mathrm{C}_{10} \mathrm{H}_{16} \mathrm{O}_{3}$ and $\mathrm{C}_{9} \mathrm{H}_{14} \mathrm{O}_{3}$ concurs with the modelling results of a previous study that assessed the influence of ozone on limonene oxidation (Pathak et al., 2012). A positive (albeit slightly positive) correlation with ozone is only observed for particle-phase $\mathrm{C}_{8} \mathrm{H}_{14} \mathrm{O}_{3}$. The acid-ozone correlation obtained for humid conditions differs significantly from that obtained for dry conditions. The negative acidozone correlation is quite pronounced in the dry experiment cases and becomes increasingly negative (in general) for acids with relatively low carbon numbers, which is a trend that is unique to these experiments. The level of $\mathrm{C}_{10} \mathrm{H}_{16} \mathrm{O}_{3}$ (especially the particle-phase) is positively correlated with ozone levels in the dry experiments. Generally, the amount of gas-phase acids has a stronger positive correlation with the limonene consumption ( $\Delta$ limonene) under humid conditions compared with dry experiments. In the dry experiments, $\mathrm{C}_{10} \mathrm{H}_{16} \mathrm{O}_{5}$ and $\mathrm{C}_{9} \mathrm{H}_{14} \mathrm{O}_{4}$ are the only acids with a strong positive correlation to $\Delta$ limonene. Compared with the occurrence of gas-phase acids, the occurrence of particlephase acids is (in general) more strongly correlated with $\Delta$ limonene.

\subsection{Model results and comparison with experiments}

Model calculations using the scheme presented by the master chemical mechanism (MCM v3.3.1; Saunders et al., 2003) were performed for all 33 experimental conditions, in order to calculate $\Delta$ limonene and radical concentrations as well as product distributions, based on the experimental conditions. The model only considered the gas-phase scheme of the MCM. Most of the previously reported carboxylic acid molecular formulas (see Table S1) are included in the MCM, which was originally developed to provide accurate, robust and current information regarding the role of specific organic compounds in ground-level ozone formation, in relation to air-quality policy development in Europe. Over the years, the MCM has been employed for models in studies linked to SOA formation (Jenkin, 2004), although this mechanism is still under development with respect to capturing descriptions on the fraction of low-volatility and often very oxygenated organic compounds (Barley et al., 2011).

Generally, the model provides a small variation in the total molar yield for the large carboxylic acids $\left(\mathrm{C}_{7}-\mathrm{C}_{10}\right)$ of $10 \%-15 \%$, whereas the experiments show larger variability (2\%-23\% molar yield); this is plausible due to the complication of aerosol formation not covered by the model. A key to understanding the chemical mechanism leading to various products is the radical distribution. The experimental set-up requiring the product distribution to be measured at the end of the flow reactor restricts dynamic information. However, the variation of the radical distribution between experiments is illustrated in Table 1 . Here the values of radicals are given as the integral concentration over the reaction time (unit ppbs). Furthermore, the integral $\mathrm{HO}_{2} / \mathrm{RO}_{2}$ ratio is presented along with a rate-normalised ratio of these reactions, i.e. the $\mathrm{HO}_{2}+\mathrm{RO}_{2}$ reaction is rapid and the typical rate constant is 1 order of magnitude larger than that of the $\mathrm{RO}_{2}+\mathrm{RO}_{2}$ self-reaction (Orlando and Tyndall, 2012).

Regarding oxidant/radical variation, the modelled $\mathrm{OH}$ levels decrease with the initial limonene concentration, except for the highest ozone cases. High-ozone experiments yield the highest $\mathrm{OH}$ dose. The model results show that the $\mathrm{HO}_{2} / \mathrm{RO}_{2}$ ratio in experiments employing the $\mathrm{OH}$ scavenger 2-butanol is approximately 1 order of magnitude higher than that of the mixed oxidant experiments. This higher ratio results from the $\mathrm{HO}_{2}$ radicals generated by the reaction of 2butanol with $\mathrm{OH}$ and have more influence over the $\mathrm{HO}_{2}+$ $\mathrm{RO}_{2}$ reaction in the experiment with a scavenger. However, the $\mathrm{RO}_{2}$ self-reaction is still the major pathway in these experiments, with twice the normalised rate of the $\mathrm{HO}_{2}$ reaction. One may note that the $\mathrm{RO}_{2}$ reaction rates are very much structure dependent and might be faster or slower than the assumed rates (see Jenkin et al. (2019) for a recent review on $\mathrm{RO}_{2}$ chemistry).

In the MCMv3.3.1, 25 closed-shell carboxylic acids with 16 different chemical formulas are included for limonene. We identify 11 of the 16 acids (Tables S4 and S5; all MCM species used in the model are presented in Table S6). $\mathrm{C}_{9} \mathrm{H}_{14} \mathrm{O}_{3}$ and $\mathrm{C}_{9} \mathrm{H}_{14} \mathrm{O}_{4}$ are the most dominant and secondmost dominant acids in the 33 modelled experiments, respectively. $\mathrm{C}_{10} \mathrm{H}_{16} \mathrm{O}_{3}$ (LIMONONIC), formed by the reaction of $\mathrm{sCI}+$ water, is the only acid that exhibits an overall positive water dependence. The model calculations predict that water should also have a positive influence on KLIMONONIC and $\mathrm{CO} 25 \mathrm{C} 6 \mathrm{CO} 2 \mathrm{H}$. However, this influence is undetectable in our experiments, owing to the extremely low concentrations of these compounds and the stronger influence exerted on other compounds with the same molecular mass.

The model predicts that the presence of $\mathrm{OH}$ radicals has a greater influence on the product distribu- 
tion, compared with the presence of water. Most individual species from the MCM exert a strong positive $\mathrm{OH}$ chemistry effect in the model, except for LIMONONIC $\left(\mathrm{C}_{10} \mathrm{H}_{16} \mathrm{O}_{3}\right), \mathrm{C} 823 \mathrm{CO} 3 \mathrm{H}\left(\mathrm{C}_{9} \mathrm{H}_{14} \mathrm{O}_{5}\right), \mathrm{C} 823 \mathrm{OOH}\left(\mathrm{C}_{8} \mathrm{H}_{14} \mathrm{O}_{4}\right)$ and $\mathrm{C} 825 \mathrm{OOH}\left(\mathrm{C}_{8} \mathrm{H}_{12} \mathrm{O}_{5}\right)$. In all cases, the concentrations of the last three compounds estimated with the model are highest when the $\mathrm{OH}$ chemistry is "turned off" (2-butanol added in model). $\mathrm{C} 82 \mathrm{CO} 2 \mathrm{H}\left(\mathrm{C}_{9} \mathrm{H}_{14} \mathrm{O}_{3}\right)$ is produced to a lesser extent under humid and high-ozone conditions and for the highest $\mathrm{OH}$ conditions. It was produced to a higher extent under medium and low ozone and for the medium and lowest $\mathrm{OH}$ conditions. In the presence of $\mathrm{OH}$ chemistry, the LIMONONIC concentration is lower under humid conditions than under dry conditions. The presence of $\mathrm{OH}$ is essential for the formation of numerous compounds and only yields a significant concentration in the absence of 2-butanol, i.e. the modelled concentrations are close to zero in the presence of 2-butanol. For example, $\mathrm{C} 731 \mathrm{CO} 2 \mathrm{H}$, KLIMONIC and KLIMONONIC are formed by ozone attack on the limona ketone which, in the model, is formed by the initial $\mathrm{OH}$ attack on the exocyclic double bond of limonene. Owing to the presence of 2-butanol, this attack on the double bond is reduced, minimising the amount of products generated. The correlation results for the humid and dry cases show that $\mathrm{C} 823 \mathrm{CO} 3 \mathrm{H}, \mathrm{C} 823 \mathrm{OOH}$ and $\mathrm{C} 825 \mathrm{OOH}$ are negatively correlated with $\mathrm{OH}$ levels in the model. The reaction with $\mathrm{OH}$ represents the only destruction pathway for the acids produced in the model (even if unsaturated). This negative correlation indicates that the $\mathrm{OH}$-induced destruction of the respective acid dominates over acid production as the $\mathrm{OH}$ levels increase. However, the reactions of unsaturated acids with ozone are not included in the MCM.

The experimental results reveal that the four dominant compounds are $\mathrm{C}_{8} \mathrm{H}_{12} \mathrm{O}_{4}, \mathrm{C}_{8} \mathrm{H}_{12} \mathrm{O}_{5}, \mathrm{C}_{9} \mathrm{H}_{14} \mathrm{O}_{4}$ and $\mathrm{C}_{9} \mathrm{H}_{14} \mathrm{O}_{5}$. However, $\mathrm{C}_{9} \mathrm{H}_{14} \mathrm{O}_{3}$, which plays only a minor role in the experiments, represents the dominant compound in the modelling results. $\mathrm{C}_{8} \mathrm{H}_{12} \mathrm{O}_{4}$, which contributes significantly to the experimental results, is characterised by a mediumlevel contribution to the model. $\mathrm{C}_{8} \mathrm{H}_{12} \mathrm{O}_{4}$ and $\mathrm{C}_{8} \mathrm{H}_{12} \mathrm{O}_{5}$ exhibit a positive $\mathrm{OH}$-dependence in the model that is consistent with the gas-phase results obtained for $\mathrm{C}_{8} \mathrm{H}_{12} \mathrm{O}_{4}$ under humid low-ozone and all medium-ozone experiments. The estimated concentration of $\mathrm{C}_{8} \mathrm{H}_{12} \mathrm{O}_{5}$ is lower in the presence of $\mathrm{OH}$ chemistry for most conditions except for humid low-ozone experiments. The model reveals a positive $\mathrm{OH}$ dependence and a negative $\mathrm{OH}$ dependence for $\mathrm{C}_{9} \mathrm{H}_{14} \mathrm{O}_{4}$ and $\mathrm{C}_{9} \mathrm{H}_{14} \mathrm{O}_{5}$, respectively. The behaviour of the $\mathrm{C}_{9} \mathrm{H}_{14} \mathrm{O}_{4}$ gas phase concurs with the model results for low- and mediumozone experiments. For the highest ozone-level experiments, the levels observed for mixed oxidation are lower than those observed for oxidation in the presence of an $\mathrm{OH}$ scavenger. The $\mathrm{OH}$ dependence of $\mathrm{C}_{9} \mathrm{H}_{14} \mathrm{O}_{5}$ in the experimental results differs from the overall negative $\mathrm{OH}$ dependence of modelled $\mathrm{C}_{9} \mathrm{H}_{14} \mathrm{O}_{5}$. In contrast to the model predictions, the $\mathrm{C}_{7}$ acids $\mathrm{C}_{7} \mathrm{H}_{10} \mathrm{O}_{4}$ and $\mathrm{C}_{7} \mathrm{H}_{12} \mathrm{O}_{3}$ contribute significantly to the gas- phase results and exhibit only a weak $\mathrm{OH}$ dependency. The model predicts a weak $\mathrm{OH}$ dependence for $\mathrm{C}_{10} \mathrm{H}_{16} \mathrm{O}_{3}$ which is in stark contrast to the strong dependence revealed by the experimental results. Overall, most acids exhibit a positive $\mathrm{RH}$ dependence in the medium-ozone and humid low-ozone cases, which is a behaviour that is lacking from the modelling results. However, consistent with the modelling results, water in the system increases the concentration of $\mathrm{C}_{10} \mathrm{H}_{16} \mathrm{O}_{3}$ by a factor of 2. This hold true for all cases, except for the highest ozone cases where the concentrations observed in the experiments are higher than the values predicted for dry conditions. In conclusion, significant concentrations of 11 acids (from a total of 16) included in the MCM are measured with the CIMS. The model predictions are, in some cases, inconsistent with the measurement results, with the most notable inconsistencies occurring for the $\mathrm{OH}$ dependency.

\section{Mechanism interpretation and outlook}

The formation and dependence of the eight most prominent ions in the experiments are only partly explained by the model and e.g. the reaction pathways that form compounds with the molecular formulas $\mathrm{C}_{7} \mathrm{H}_{10} \mathrm{O}_{3}$ and $\mathrm{C}_{10} \mathrm{H}_{16} \mathrm{O}_{4}$ are absent. In the following, we propose reaction pathways for explaining the formation of some ions not accounted for in the model and propose additional pathways for compounds already included in the MCM. Examples include the reactions of unsaturated acid products with ozone or the formation of $\mathrm{C}_{10}$ acyl radicals via the hot acid channel (see pathway $\mathrm{A}$ in Fig. 1). The largest discrepancy between model and experimental results is observed for the formation of compounds, such as the group of $\mathrm{C}_{7}$ acids or ketolimononic, -limonic or -limonalic acid which are OH-dependent in the model but are $\mathrm{OH}$-independent in the observations. The dominance of $\mathrm{C}_{9} \mathrm{H}_{14} \mathrm{O}_{4}$ and the positive correlation with ozone can be explained by the additional formation of ketolimononic acid via reaction pathways, as seen in Fig. 5. Here, ozone attacks the double bond of the primary product limononic acid, forming a CI. In the case of exocyclic CI, sCI can be formed directly and the remaining $\mathrm{CI}^{*}$ are usually more effectively stabilised than endocyclic $\mathrm{CI}^{*}$; therefore, a larger yield of sCI can be expected. The sCI produced can produce ketolimononic acid via the water channel (see Fig. 5). Ketolimonalic $\left(\mathrm{C}_{8} \mathrm{H}_{12} \mathrm{O}_{4}\right)$ and ketolimonic $\left(\mathrm{C}_{8} \mathrm{H}_{12} \mathrm{O}_{5}\right)$ acid may be formed via the reaction of limonalic (R3 in Fig. 5, $\mathrm{C}_{9} \mathrm{H}_{14} \mathrm{O}_{3}$ ) and limonic acid (R2 in Fig. 5, $\mathrm{C}_{9} \mathrm{H}_{14} \mathrm{O}_{4}$ ), respectively, with ozone. The formation of a vinyl hydro peroxide (VHP) and its subsequent decomposition via $\mathrm{OH}$ elimination and oxygen addition to the alkyl radical yields an alkyl peroxy radical. The bimolecular reaction of the alkyl peroxy with other $\mathrm{RO}_{2}$ can lead to an alkoxy radical which can then form a carbonyl and $\mathrm{HO}_{2}$ upon reacting with oxygen. This reaction chain may explain the formation of $\mathrm{C}_{9} \mathrm{H}_{12} \mathrm{O}_{5}$ and $\mathrm{C}_{8} \mathrm{H}_{10} \mathrm{O}_{5-6}$. 


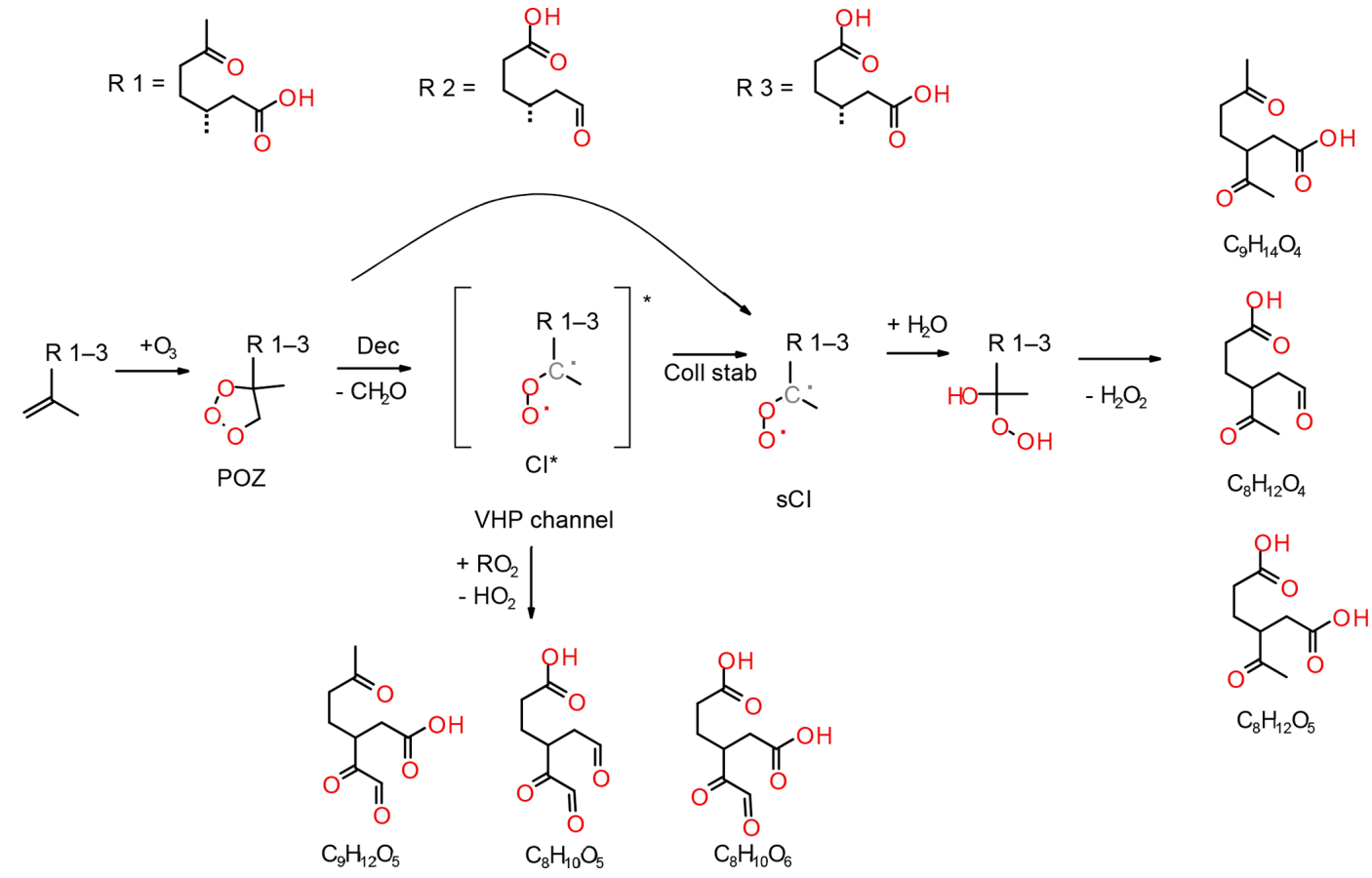

Figure 5. Proposed reaction mechanisms for secondary ozone chemistry of limononic (R1), limonic (R2) and limonalic (R3) acid. The dotted bond shows where R1-3 is connected to the 2-methyl-ethenyl group (i.e. $-\mathrm{C}\left(\mathrm{CH}_{3}\right)=\mathrm{CH}_{2}$ ) in the parent compounds.

(a)

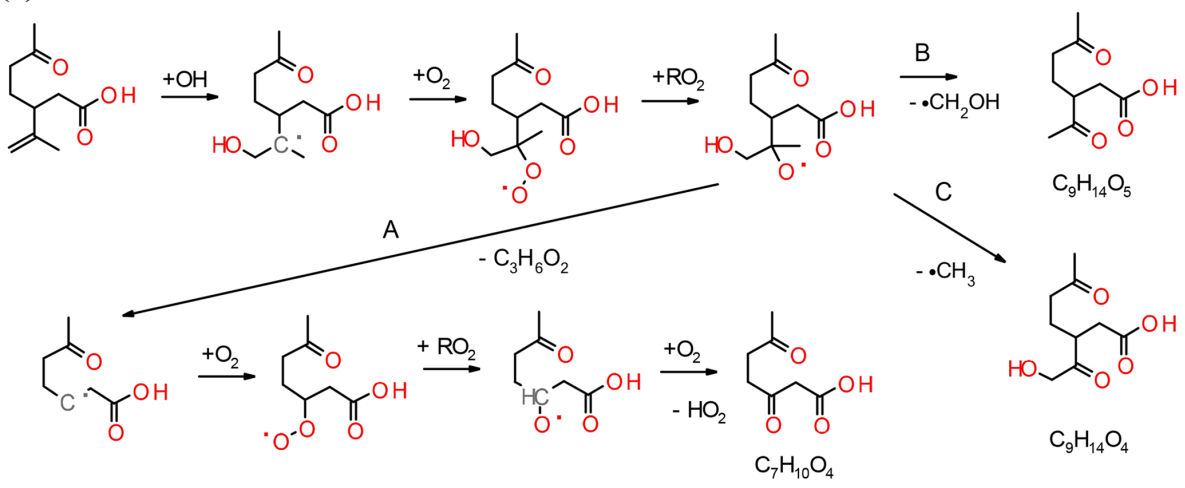

(b)

$$
\text { (n) }
$$

Figure 6. (a) Secondary chemistry of the addition of $\mathrm{OH}$ to the unsaturated double bond of the primary product limononic acid and the subsequent formation of $\mathrm{C}_{7} \mathrm{H}_{10} \mathrm{O}_{4}, \mathrm{C}_{9} \mathrm{H}_{14} \mathrm{O}_{5}$ and $\mathrm{C}_{9} \mathrm{H}_{14} \mathrm{O}_{4}$. (b) Secondary chemistry of a selected saturated carboxylic acid product $\left(\mathrm{C}_{8} \mathrm{H}_{12} \mathrm{O}_{5}\right)$ giving the observed $\mathrm{C}_{7}$ products. 
The model predictions for cases with and without the scavenger only differ slightly, but the reaction pathway involving $\mathrm{OH}$ is an important contributor to $\mathrm{C}_{10} \mathrm{H}_{16} \mathrm{O}_{3}$ formation in the experiments. This becomes especially clear when dry experiments with/without $\mathrm{OH}$ (with no possibility for the water pathway) are compared. The pathway leading to the formation of $\mathrm{C}_{10} \mathrm{H}_{16} \mathrm{O}_{3}$ via the hot acid channel from the anti-CI* (see Fig. 1) is also neglected by the model. Figure 6 illustrates how the remaining double bond can also be attacked by $\mathrm{OH}$ which would lead to the formation of an alkyl radical and the subsequent addition of $\mathrm{O}_{2}$. The reaction pathways shown in Fig. 6 lead to the observed acid formation and may explain the formation of $\mathrm{C}_{7} \mathrm{H}_{10} \mathrm{O}_{4}, \mathrm{C}_{9} \mathrm{H}_{14} \mathrm{O}_{5}$ and $\mathrm{C}_{9} \mathrm{H}_{14} \mathrm{O}_{4}$. The alkoxy radical produced will probably follow pathway A which produces the most stable radical and, subsequently, $\mathrm{C}_{7} \mathrm{H}_{10} \mathrm{O}_{4}$. This pathway involves two bimolecular steps and is positively correlated with $\mathrm{RO}_{2}$ levels in the system. Saturated compounds, although non-reactive with ozone, are susceptible to secondary chemical reactions induced by $\mathrm{OH}$. Figure $6 \mathrm{~b}$ illustrates how the fate of the saturated compounds depends on the relative reactivity of different sites to $\mathrm{OH}$, and may include the abstraction of the acidic hydrogen followed by the splitting off of $\mathrm{CO}_{2}$; the subsequent bimolecular reactions will produce $\mathrm{C}_{7} \mathrm{H}_{10} \mathrm{O}_{4}$. This reaction competes with the abstraction of the tertiary hydrogen, but will lead to products that are inconsequential to the present experimental results. The formation of $\mathrm{C}_{10} \mathrm{H}_{16} \mathrm{O}_{4}$ results from processes other than ozonolysis or $\mathrm{OH}$ attack on the exocyclic double bond of an acid product due to the fragmentation of the POZ produced and excessively high resulting oxygen numbers. $\mathrm{C}_{10} \mathrm{H}_{16} \mathrm{O}_{4}$ may have resulted from the reaction of an acyl peroxy radical with $\mathrm{HO}_{2}$ (see Fig. 1) and the formation of a peroxy acid. However, the pathway for $\mathrm{C}_{7} \mathrm{H}_{10} \mathrm{O}_{3}$ formation remains unclear. For the particle phase, $\mathrm{C}_{8} \mathrm{H}_{12} \mathrm{O}_{5}$ and $\mathrm{C}_{9} \mathrm{H}_{14} \mathrm{O}_{5}$ are the dominant compounds in most of the experiments performed in this study, whereas $\mathrm{C}_{10} \mathrm{H}_{16} \mathrm{O}_{3}$ (a major gas-phase compound) only represents a minor contributor to this phase. $\mathrm{C}_{10} \mathrm{H}_{16} \mathrm{O}_{4}$ is excluded in the model, but plays a role in the particle-phase results. The formation of $\mathrm{C}_{10} \mathrm{H}_{16} \mathrm{O}_{4}$ is positively correlated with the presence of $\mathrm{RO}_{2}$ and $\mathrm{HO}_{2} \cdot \mathrm{C}_{9} \mathrm{H}_{14} \mathrm{O}_{3}$ and $\mathrm{C}_{9} \mathrm{H}_{14} \mathrm{O}_{4}$ are the dominant acids in the model calculations, but are only minor compounds in the particle phase. $\mathrm{C}_{9} \mathrm{H}_{14} \mathrm{O}_{4}$ formation only seems to occur in experiments with the highest limonene content. Rapid autoxidation for the formation of highly oxidised molecules (HOMs) has recently gained significant attention (Ehn et al., 2014). This autoxidation proceeds via intramolecular $\mathrm{H}$ abstraction of $\mathrm{RO}_{2}$ and the subsequent formation of hydroperoxide groups. $\mathrm{RO}_{2}$ lifetimes in low- $\mathrm{NO}_{x}$ environments are usually sufficient for the occurrence of this process (Orlando and Tyndall, 2012). During this process, large amounts of oxygen are rapidly introduced into the molecules, leading to a decrease in their vapour pressure. Most of the $\mathrm{RO}_{2}$ will originate from the VHP channel, in the case of limonene ozonolysis, and products will probably be non-identifiable
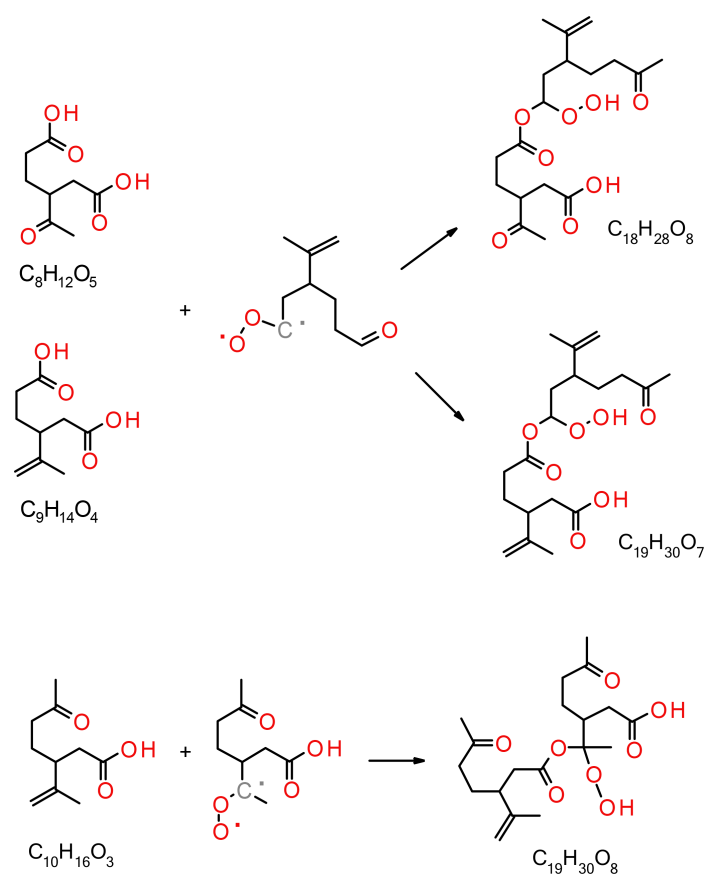

Figure 7. Proposed formation of observed dimers $\left(\mathrm{C}_{18} \mathrm{H}_{28} \mathrm{O}_{8}\right.$, $\mathrm{C}_{19} \mathrm{H}_{20} \mathrm{O}_{7}$ and $\mathrm{C}_{19} \mathrm{H}_{30} \mathrm{O}_{8}$ ) from monomer-Criegee reactions.

unless the radical termination reaction yields a carboxylic acid. Even if the compounds formed contain one or more carboxylic acid group, the corresponding low vapour pressure may be undetectable by the FIGAERO inlet used. Jokinen et al. (2014) investigated the formation of HOM from limonene and found that highly oxygenated monomers $\left(\mathrm{C}_{10}\right)$ and dimers $\left(\mathrm{C}_{20}\right)$ with oxygen numbers ranging from 5 to 11 and 7 to 18 , respectively, play a crucial role in this formation. Only one compound with the same chemical formula $\left(\mathrm{C}_{9} \mathrm{H}_{14} \mathrm{O}_{5}\right)$ has been found in this study, but it is unclear if the chemical structure is the same.

In this study, dimers have exclusively been detected in the particle phase and are absent from the gas phase, owing to their potentially low vapour pressure. The formation of dimer esters from $\alpha$-pinene ozonolysis has recently been investigated by Kristensen et al. (2016). In that work, the reaction of sCI with carboxylic acids, suggested as the formation pathway in the gas phase, was followed by partitioning into the particle phase. Consequently, the carboxylic acid group is lost in the esterification process which may explain the relatively low signals observed for acidic dimers in the present study. A potential acidic dimer ester will only be detectable if the dimer has a carboxylic acid group, as in the case of a di- or tricarboxylic acid, or if the sCI carries a carboxylic acid group. Unsaturated dimers may react with ozone. $\mathrm{C}_{18} \mathrm{H}_{28} \mathrm{O}_{8}$ and $\mathrm{C}_{19} \mathrm{H}_{30} \mathrm{O}_{7}$ can form via the reaction of the endocyclic limonene sCI with ketolimonic $\left(\mathrm{C}_{8} \mathrm{H}_{12} \mathrm{O}_{5}\right)$ or limonic $\left(\mathrm{C}_{9} \mathrm{H}_{14} \mathrm{O}_{4}\right)$ acid, respectively (see Fig. 7). In addition, $\mathrm{C}_{19} \mathrm{H}_{30} \mathrm{O}_{8}$ may be formed from the dimerisation re- 

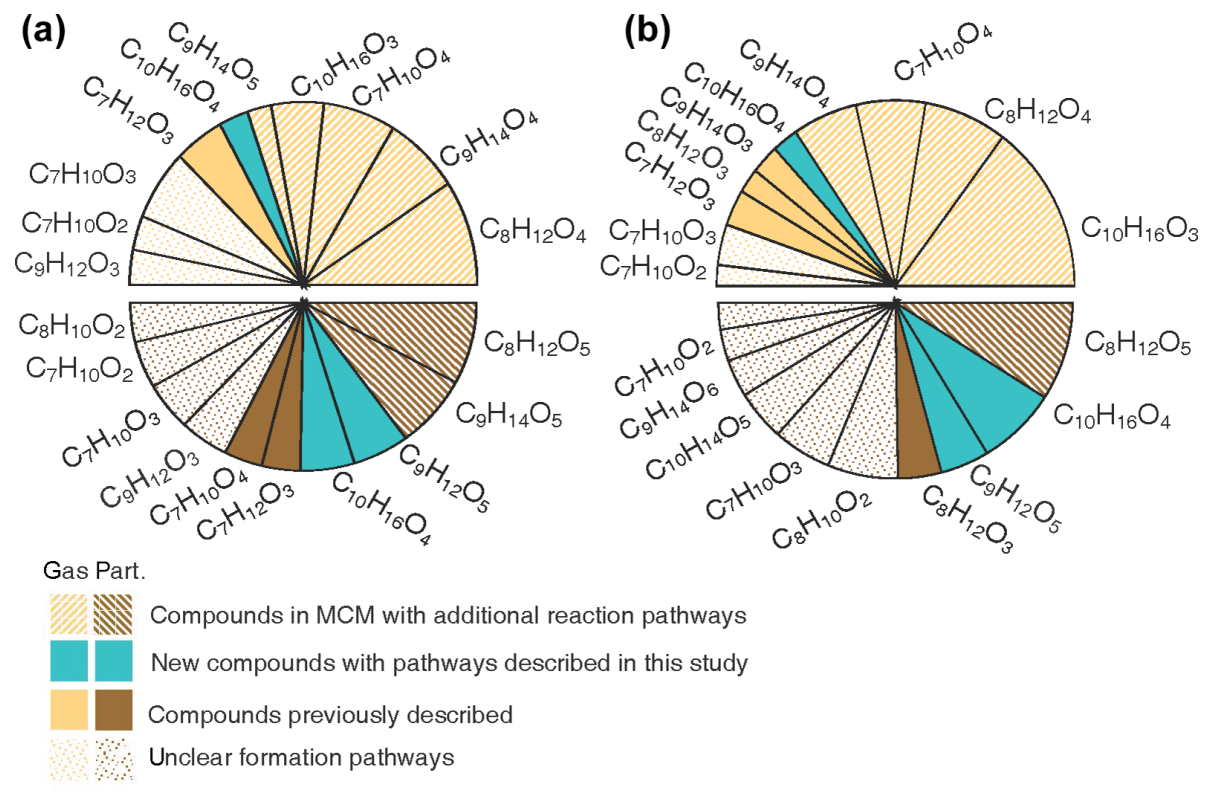

Figure 8. Pie charts showing the percentage contribution of each compound for the 10 major compounds observed. The top half of the pies shows the gas-phase data, and the bottom half of the pies shows the particle-phase data. The compounds are classified according to current knowledge, i.e. previously described reaction mechanism, mechanism suggested in this study and unclear formation pathways. (a) The averaged contribution for all experiments. (b) The specific contributions for Experiment 1, which had the lowest concentrations of reactants with mixed oxidants and humid conditions.

action of limononic acid and the limononic-sCI. Gas-phase dimerisation reactions of dominating $\mathrm{C}_{7}-\mathrm{C}_{10}$ acids with $\mathrm{sCI}$ account for only some of the dimer formulas. Reactions of acids with relatively small carbon numbers $\left(<\mathrm{C}_{7}\right), \mathrm{RO}_{2}$ dimerisation reactions or condensed-phase reactions may account for the other formulas.

\section{Conclusion}

Figure 8a provides an overview of the most important acidic compounds found in this study. These are identified by comparing the average contribution of each compound to all 33 experiments. Explicit formation pathways for the $\mathrm{C}_{10} \mathrm{H}_{16} \mathrm{O}_{4}$ and $\mathrm{C}_{9} \mathrm{H}_{12} \mathrm{O}_{5}$ compounds implemented in the model and additional reaction pathways for $\mathrm{C}_{7} \mathrm{H}_{10} \mathrm{O}_{4}$, $\mathrm{C}_{8} \mathrm{H}_{12} \mathrm{O}_{4-5}, \mathrm{C}_{9} \mathrm{H}_{14} \mathrm{O}_{4-5}$ and $\mathrm{C}_{10} \mathrm{H}_{16} \mathrm{O}_{3}$ are proposed. Structures for $\mathrm{C}_{10} \mathrm{H}_{14} \mathrm{O}_{5}$ and $\mathrm{C}_{10} \mathrm{H}_{16} \mathrm{O}_{4}$ have been proposed in previous studies (Jaoui et al., 2006; Rossignol et al., 2012; Leungsakul et al., 2005a; Walser et al., 2008; Glasius et al., 2000), but the current mechanistic understanding is inadequate to explain the formation of compounds with the proposed structures. In Fig. 8a, we show that the mechanisms proposed in this work can improve the qualitative understanding of the formation characterising (on average) $65 \%$ of the dominant gas-phase compounds and $50 \%$ of the particlephase compounds. Notably, the particle-phase data correspond partly to compounds with a low oxygen content (2-3 oxygen), and their formation and negative correlation with ozone remain unclear and require further study. However, only a few acidic dimers are detected. This may have resulted from the lack of evaporation of these dimers (i.e. as acidic dimers) or the loss of the acid functional group from potential acid monomer precursors during the dimer formation, as suggested in previous studies (Kristensen et al., 2016; Witkowski and Gierczak, 2014; Wang et al., 2016). Experiment 1 , performed at low concentrations, for mixed oxidants and under humid conditions, should best represent atmospheric conditions. The summarised signal of the highest 10 acids in Experiment 1 can be qualitatively attributed to $89 \%$ of the gas phase, and the proposed mechanisms in this study account for $74 \%$ of the total signal (see Fig. 8b). The particle-phase composition can be qualitatively explained (by up to $42 \%$ ) by the mechanisms proposed in this work. The relatively large percentage of unexplained signal in the atmospheric case will result in large uncertainties when the acidic-particle phase composition of limonene SOA is modelled based on existing mechanisms (e.g. MCM) and partitioning theory.

For a more quantitative mechanism (compared with the mechanism considered), the inclusion of non-acidic products is required for a complete picture of the oxidation products. Furthermore, secondary and tertiary chemistry must be considered when the oxidation of compounds is modelled. Subsequent aerosol formation as well as dimerisation and condensed-phase reactions must also be evaluated. 
Data availability. The data used in this study are available upon request from the authors.

Supplement. The supplement related to this article is available online at: https://doi.org/10.5194/acp-19-13037-2019-supplement.

Author contributions. The experiments were designed by JH with support from CF. Data collection and interpretation were carried out by $\mathrm{JH}$ with support from AL. MH designed the project. The paper was written by JH with support from MH and TM. All co-authors provided article feedback and comments.

Competing interests. The authors declare that they have no conflict of interest.

Financial support. This research has been supported by the Vetenskapsrådet (grant nos. 2013-06917 and 2014-05332) and the Svenska Forskningsrådet Formas (grant no. 2015-1537).

Review statement. This paper was edited by Alexander Laskin and reviewed by two anonymous referees.

\section{References}

Atkinson, R., Aschmann, S. M., Arey, J., and Shorees, B.: Formation of $\mathrm{OH}$ radicals in the gas phase reactions of $\mathrm{O}_{3}$ with a series of terpenes, J. Geophys. Res., 97, 6065-6073, https://doi.org/10.1029/92jd00062, 1992.

Barley, M. H., Topping, D., Lowe, D., Utembe, S., and McFiggans, G.: The sensitivity of secondary organic aerosol (SOA) component partitioning to the predictions of component properties - Part 3: Investigation of condensed compounds generated by a near-explicit model of VOC oxidation, Atmos. Chem. Phys., 11, 13145-13159, https://doi.org/10.5194/acp-11-131452011, 2011.

Bertram, T. H., Kimmel, J. R., Crisp, T. A., Ryder, O. S., Yatavelli, R. L. N., Thornton, J. A., Cubison, M. J., Gonin, M., and Worsnop, D. R.: A field-deployable, chemical ionization timeof-flight mass spectrometer, Atmos. Meas. Tech., 4, 1471-1479, https://doi.org/10.5194/amt-4-1471-2011, 2011.

Brown, S. K., Sim, M. R., Abramson, M. J., and Gray, C. N.: Concentrations of Volatile Organic-Compounds in Indoor Air - a Review, Indoor Air, 4, 123-134, https://doi.org/10.1111/j.16000668.1994.t01-2-00007.x, 1994.

Carslaw, N.: A mechanistic study of limonene oxidation products and pathways following cleaning activities, Atmos. Environ., 80, 507-513, https://doi.org/10.1016/j.atmosenv.2013.08.034, 2013.

Chen, J. J. and Griffin, R. J.: Modeling secondary organic aerosol formation from oxidation of alpha-pinene, betapinene, and d-limonene, Atmos. Environ., 39, 7731-7744, https://doi.org/10.1016/j.atmosenv.2005.05.049, 2005.
Chen, X. and Hopke, P. K.: A chamber study of secondary organic aerosol formation by limonene ozonolysis, Indoor Air, 20, 320 328, https://doi.org/10.1111/j.1600-0668.2010.00656.x, 2010.

Ehn, M., Thornton, J. A., Kleist, E., Sipila, M., Junninen, H., Pullinen, I., Springer, M., Rubach, F., Tillmann, R., Lee, B., Lopez-Hilfiker, F., Andres, S., Acir, I. H., Rissanen, M., Jokinen, T., Schobesberger, S., Kangasluoma, J., Kontkanen, J., Nieminen, T., Kurten, T., Nielsen, L. B., Jorgensen, S., Kjaergaard, H. G., Canagaratna, M., Maso, M. D., Berndt, T., Petaja, T., Wahner, A., Kerminen, V. M., Kulmala, M., Worsnop, D. R., Wildt, J., and Mentel, T. F.: A large source of lowvolatility secondary organic aerosol, Nature, 506, 476-479, https://doi.org/10.1038/nature13032, 2014.

Faxon, C., Hammes, J., Le Breton, M., Pathak, R. K., and Hallquist, M.: Characterization of organic nitrate constituents of secondary organic aerosol (SOA) from nitrate-radical-initiated oxidation of limonene using high-resolution chemical ionization mass spectrometry, Atmos. Chem. Phys., 18, 5467-5481, https://doi.org/10.5194/acp-18-5467-2018, 2018.

Foley, J. P., and Dorsey, J. G.: A Review of the Exponentially Modified Gaussian (Emg) Function - Evaluation and Subsequent Calculation of Universal Data, J. Chromatogr. Sci., 22, 40-46, https://doi.org/10.1093/chromsci/22.1.40, 1984.

Glasius, M., Lahaniati, M., Calogirou, A., Di Bella, D., Jensen, N. R., Hjorth, J., Kotzias, D., and Larsen, B. R.: Carboxylic Acids in Secondary Aerosols from Oxidation of Cyclic Monoterpenes by Ozone, Environ. Sci. Technol., 34, 1001-1010, 2000.

Glasius, M. and Goldstein, A. H.: Recent Discoveries and Future Challenges in Atmospheric Organic Chemistry, Environ. Sci. Technol., 50, 2754-2764, https://doi.org/10.1021/acs.est.5b05105, 2016.

Gong, Y., Chen, Z., and Li, H.: The oxidation regime and SOA composition in limonene ozonolysis: roles of different double bonds, radicals, and water, Atmos. Chem. Phys., 18, 1510515123, https://doi.org/10.5194/acp-18-15105-2018, 2018.

Guenther, A. B., Jiang, X., Heald, C. L., Sakulyanontvittaya, T., Duhl, T., Emmons, L. K., and Wang, X.: The Model of Emissions of Gases and Aerosols from Nature version 2.1 (MEGAN2.1): an extended and updated framework for modeling biogenic emissions, Geosci. Model Dev., 5, 1471-1492, https://doi.org/10.5194/gmd-5-1471-2012, 2012.

Hallquist, M., Wenger, J. C., Baltensperger, U., Rudich, Y., Simpson, D., Claeys, M., Dommen, J., Donahue, N. M., George, C., Goldstein, A. H., Hamilton, J. F., Herrmann, H., Hoffmann, T., Iinuma, Y., Jang, M., Jenkin, M. E., Jimenez, J. L., Kiendler-Scharr, A., Maenhaut, W., McFiggans, G., Mentel, Th. F., Monod, A., Prévôt, A. S. H., Seinfeld, J. H., Surratt, J. D., Szmigielski, R., and Wildt, J.: The formation, properties and impact of secondary organic aerosol: current and emerging issues, Atmos. Chem. Phys., 9, 5155-5236, https://doi.org/10.5194/acp9-5155-2009, 2009.

Jaoui, M., Kleindienst, T. E., Lewandowski, M., Offenberg, J. H., and Edney, E. O.: Identification and quantification of aerosol polar oxygenated compounds bearing carboxylic or hydroxyl groups. 2. Organic tracer compounds from monoterpenes, Environ. Sci. Technol., 39, 5661-5673, 2005.

Jaoui, M., Corse, E., Kleindienst, T. E., Offenberg, J. H., Lewandowski, M., and Edney, E. O.: Analysis of Secondary Organic Aerosol Compounds from the Photooxidation 
ofd-Limonene in the Presence of $\mathrm{NO}_{x}$ and their Detection in Ambient $\mathrm{PM}_{2.5}$, Environ. Sci. Technol., 40, 3819-3828, https://doi.org/10.1021/es052566z, 2006.

Jenkin, M. E.: Modelling the formation and composition of secondary organic aerosol from $\alpha$ - and $\beta$-pinene ozonolysis using MCM v3, Atmos. Chem. Phys., 4, 1741-1757, https://doi.org/10.5194/acp-4-1741-2004, 2004.

Jenkin, M. E., Valorso, R., Aumont, B., and Rickard, A. R.: Estimation of rate coefficients and branching ratios for reactions of organic peroxy radicals for use in automated mechanism construction, Atmos. Chem. Phys., 19, 7691-7717, https://doi.org/10.5194/acp-19-7691-2019, 2019.

Jokinen, T., Sipila, M., Richters, S., Kerminen, V. M., Paasonen, P., Stratmann, F., Worsnop, D., Kulmala, M., Ehn, M., Herrmann, H., and Berndt, T.: Rapid autoxidation forms highly oxidized $\mathrm{RO}_{2}$ radicals in the atmosphere, Angew. Chem. Int. Edit., 53, 14596-14600, https://doi.org/10.1002/anie.201408566, 2014.

Jonsson, Å. M., Hallquist, M., and Ljungström, E.: Impact of Humidity on the Ozone Initiated Oxidation of Limonene, $\Delta 3$ Carene, and $\alpha$-Pinene, Environ. Sci. Technol., 40, 188-194, https://doi.org/10.1021/es051163w, 2006.

Jonsson, A. M., Hallquist, M., and Ljungström, E.: The effect of temperature and water on secondary organic aerosol formation from ozonolysis of limonene, $\Delta^{3}$-carene and $\alpha$-pinene, Atmos. Chem. Phys., 8, 6541-6549, https://doi.org/10.5194/acp-8-65412008, 2008a.

Jonsson, Å. M., Hallquist, M., and Ljungström, E.: Influence of $\mathrm{OH}$ Scavenger on the Water Effect on Secondary Organic Aerosol Formation from Ozonolysis of Limonene, $\Delta 3$ Carene, and $\alpha$-Pinene, Environ. Sci. Technol., 42, 5938-5944, https://doi.org/10.1021/es702508y, 2008b.

Keywood, M. D., Kroll, J. H., Varutbangkul, V., Bahreini, R., Flagan, R. C., and Seinfeld, J. H.: Secondary Organic Aerosol Formation from Cyclohexene Ozonolysis: Effect of $\mathrm{OH}$ Scavenger and the Role of Radical Chemistry, Environ. Sci. Technol., 38, 3343-3350, https://doi.org/10.1021/es049725j, 2004.

Koch, S., Winterhalter, R., Uherek, E., Kolloff, A., Neeb, P., and Moortgat, G. K.: Formation of new particles in the gas-phase ozonolysis of monoterpenes, Atmos. Environ., 34, 4031-4042, 2000.

Kristensen, K., Enggrob, K. L., King, S. M., Worton, D. R., Platt, S. M., Mortensen, R., Rosenoern, T., Surratt, J. D., Bilde, M., Goldstein, A. H., and Glasius, M.: Formation and occurrence of dimer esters of pinene oxidation products in atmospheric aerosols, Atmos. Chem. Phys., 13, 3763-3776, https://doi.org/10.5194/acp13-3763-2013, 2013.

Kristensen, K., Cui, T., Zhang, H., Gold, A., Glasius, M., and Surratt, J. D.: Dimers in $\alpha$-pinene secondary organic aerosol: effect of hydroxyl radical, ozone, relative humidity and aerosol acidity, Atmos. Chem. Phys., 14, 4201-4218, https://doi.org/10.5194/acp-14-4201-2014, 2014.

Kristensen, K., Watne, Å. K., Hammes, J., Lutz, A., Petäjä, T., Hallquist, M., Bilde, M., and Glasius, M.: High-Molecular Weight Dimer Esters Are Major Products in Aerosols from $\alpha$-Pinene Ozonolysis and the Boreal Forest, Environ. Sci. Technol. Lett., 3, 280-285, https://doi.org/10.1021/acs.estlett.6b00152, 2016.

Langer, S., Moldanova, J., Arrhenius, K., Ljungstrom, E., and Ekberg, L.: Ultrafine particles produced by ozone/limonene reactions in indoor air under low/closed ventilation conditions, Atmos. Environ., 42, 4149-4159, https://doi.org/10.1016/j.atmosenv.2008.01.034, 2008.

Le Breton, M., Psichoudaki, M., Hallquist, M., Watne, A. K., Lutz, A., and Hallquist, A. M.: Application of a FIGAERO ToF CIMS for on-line characterization of real-world fresh and aged particle emissions from buses, Aerosol Sci. Technol., 53, 244-259, https://doi.org/10.1080/02786826.2019.1566592, 2019.

Leungsakul, S., Jaoui, M., and Kamens, R. M.: Kinetic mechanism for predicting secondary organic aerosol formation from the reaction of d-limonene with ozone, Environ. Sci. Technol., 39, 9583-9594, 2005a.

Leungsakul, S., Jeffries, H. E., and Kamens, R. M.: A kinetic mechanism for predicting secondary aerosol formation from the reactions of d-limonene in the presence of oxides of nitrogen and natural sunlight, Atmos. Environ., 39, 7063-7082, 2005b.

Lopez-Hilfiker, F. D., Mohr, C., Ehn, M., Rubach, F., Kleist, E., Wildt, J., Mentel, Th. F., Lutz, A., Hallquist, M., Worsnop, D., and Thornton, J. A.: A novel method for online analysis of gas and particle composition: description and evaluation of a Filter Inlet for Gases and AEROsols (FIGAERO), Atmos. Meas. Tech., 7, 983-1001, https://doi.org/10.5194/amt-7-983-2014, 2014.

Lopez-Hilfiker, F. D., Mohr, C., Ehn, M., Rubach, F., Kleist, E., Wildt, J., Mentel, Th. F., Carrasquillo, A. J., Daumit, K. E., Hunter, J. F., Kroll, J. H., Worsnop, D. R., and Thornton, J. A.: Phase partitioning and volatility of secondary organic aerosol components formed from $\alpha$-pinene ozonolysis and $\mathrm{OH}$ oxidation: the importance of accretion products and other low volatility compounds, Atmos. Chem. Phys., 15, 7765-7776, https://doi.org/10.5194/acp-15-7765-2015, 2015.

Maksymiuk, C. S., Gayahtri, C., Gil, R. R., and Donahue, N. M.: Secondary organic aerosol formation from multiphase oxidation of limonene by ozone: mechanistic constraints via twodimensional heteronuclear NMR spectroscopy, Phys. Chem. Chem. Phys., 11, 7810-7818, https://doi.org/10.1039/b820005j, 2009.

McFiggans, G., Mentel, T. F., Wildt, J., Pullinen, I., Kang, S., Kleist, E., Schmitt, S., Springer, M., Tillmann, R., Wu, C., Zhao, D., Hallquist, M., Faxon, C., Le Breton, M., Hallquist, Å. M., Simpson, D., Bergström, R., Jenkin, M. E., Ehn, M., Thornton, J. A., Alfarra, M. R., Bannan, T. J., Percival, C. J., Priestley, M., Topping, D., and Kiendler-Scharr, A.: Secondary organic aerosol reduced by mixture of atmospheric vapours, Nature, 565, 587-593, https://doi.org/10.1038/s41586-018-0871-y, 2019.

Mohr, C., Lopez-Hilfiker, F. D., Zotter, P., Prévôt, A. S. H., Xu, L., Ng, N. L., Herndon, S. C., Williams, L. R., Franklin, J. P., Zahniser, M. S., Worsnop, D. R., Knighton, W. B., Aiken, A. C., Gorkowski, K. J., Dubey, M. K., Allan, J. D., and Thornton, J. A.: Contribution of Nitrated Phenols to Wood Burning Brown Carbon Light Absorption in Detling, United Kingdom during Winter Time, Environ. Sci. Technol., 47, 6316-6324, https://doi.org/10.1021/es400683v, 2013.

Mohr, C., Lopez-Hilfiker, F. D., Yli-Juuti, T., Heitto, A., Lutz, A., Hallquist, M., D’Ambro, E. L., Rissanen, M. P., Hao, L. Q., Schobesberger, S., Kulmala, M., Mauldin, R. L., Makkonen, U., Sipila, M., Petaja, T., and Thornton, J. A.: Ambient observations of dimers from terpene oxidation in the gas phase: Implications for new particle formation and growth, Geophys. Res. Lett., 44, 2958-2966, https://doi.org/10.1002/2017gl072718, 2017. 
Orlando, J. J. and Tyndall, G. S.: Laboratory studies of organic peroxy radical chemistry: an overview with emphasis on recent issues of atmospheric significance, Chem. Soc. Rev., 41, 62946317, https://doi.org/10.1039/c2cs35166h, 2012.

Pathak, R. K., Salo, K., Emanuelsson, E. U., Cai, C., Lutz, A., Hallquist, A. M., and Hallquist, M.: Influence of ozone and radical chemistry on limonene organic aerosol production and thermal characteristics, Environ. Sci. Technol., 46, 11660-11669, https://doi.org/10.1021/es301750r, 2012.

Rossignol, S., Chiappini, L., Perraudin, E., Rio, C., Fable, S., Valorso, R., and Doussin, J. F.: Development of a parallel sampling and analysis method for the elucidation of gas/particle partitioning of oxygenated semi-volatile organics: a limonene ozonolysis study, Atmos. Meas. Tech., 5, 1459-1489, https://doi.org/10.5194/amt-5-1459-2012, 2012.

Rossignol, S., Rio, C., Ustache, A., Fable, S., Nicolle, J., Meme, A., D'Anna, B., Nicolas, M., Leoz, E., and Chiappini, L.: The use of a housecleaning product in an indoor environment leading to oxygenated polar compounds and SOA formation: Gas and particulate phase chemical characterization, Atmos. Environ., 75, 196-205, https://doi.org/10.1016/j.atmosenv.2013.03.045, 2013.

Saathoff, H., Naumann, K.-H., Möhler, O., Jonsson, Å. M., Hallquist, M., Kiendler-Scharr, A., Mentel, Th. F., Tillmann, R., and Schurath, U.: Temperature dependence of yields of secondary organic aerosols from the ozonolysis of $\alpha$-pinene and limonene, Atmos. Chem. Phys., 9, 1551-1577, https://doi.org/10.5194/acp9-1551-2009, 2009.

Salo, K., Jonsson, A. M., Andersson, P. U., and Hallquist, M.: Aerosol volatility and enthalpy of sublimation of carboxylic acids, J. Phys. Chem. A, 114, 4586-4594, https://doi.org/10.1021/jp910105h, 2010.

Shrivastava, M., Cappa, C. D., Fan, J. W., Goldstein, A. H., Guenther, A. B., Jimenez, J. L., Kuang, C., Laskin, A., Martin, S. T., Ng, N. L., Petaja, T., Pierce, J. R., Rasch, P. J., Roldin, P., Seinfeld, J. H., Shilling, J., Smith, J. N., Thornton, J. A., Volkamer, R., Wang, J., Worsnop, D. R., Zaveri, R. A., Zelenyuk, A., and Zhang, Q.: Recent advances in understanding secondary organic aerosol: Implications for global climate forcing, Rev. Geophys., 55, 509-559, https://doi.org/10.1002/2016rg000540, 2017.
Vereecken, L. and Francisco, J. S.: Theoretical studies of atmospheric reaction mechanisms in the troposphere, Chem. Soc. Rev., 41, 6259-6293, https://doi.org/10.1039/c2cs35070j, 2012.

Walser, M. L., Desyaterik, Y., Laskin, J., Laskin, A., and Nizkorodov, S. A.: High-resolution mass spectrometric analysis of secondary organic aerosol produced by ozonation of limonene, Phys. Chem. Chem. Phys. 10, 1009-1022, https://doi.org/10.1039/b712620d, 2008.

Wang, M., Yao, L., Zheng, J., Wang, X., Chen, J., Yang, X., Worsnop, D. R., Donahue, N. M., and Wang, L.: Reactions of Atmospheric Particulate Stabilized Criegee Intermediates Lead to High-Molecular-Weight Aerosol Components, Environ. Sci. Technol., 50, 5702-5710, https://doi.org/10.1021/acs.est.6b02114, 2016.

Watne, A. K., Westerlund, J., Hallquist, A. M., Brune, W. H., and Hallquist, M.: Ozone and $\mathrm{OH}$-induced oxidation of monoterpenes: Changes in the thermal properties of secondary organic aerosol (SOA), J. Aerosol Sci., 114, 31-41, https://doi.org/10.1016/j.jaerosci.2017.08.011, 2017.

Witkowski, B. and Gierczak, T.: Early stage composition of SOA produced by $\alpha$-pinene/ozone reaction: $\alpha$-Acyloxyhydroperoxy aldehydes and acidic dimers, Atmos. Environ., 95, 59-70, https://doi.org/10.1016/j.atmosenv.2014.06.018, 2014.

Youssefi, S. and Waring, M. S.: Transient Secondary Organic Aerosol Formation from Limonene Ozonolysis in Indoor Environments: Impacts of Air Exchange Rates and Initial Concentration Ratios, Environ. Sci. Technol., 48, 7899-7908, https://doi.org/10.1021/es5009906, 2014.

Ziemann, P. J. and Atkinson, R.: Kinetics, products, and mechanisms of secondary organic aerosol formation, Chem. Soc. Rev., 41, 6582-6605, 2012. 